\title{
Somatic calcium level reports integrated spiking activity of cerebellar interneurons in vitro and in vivo
}

\author{
Romain Franconville, ${ }^{1}$ Gaëlle Revet, ${ }^{1}$ Guadalupe Astorga, ${ }^{1}$ Beat Schwaller, ${ }^{2}$ and Isabel Llano ${ }^{1}$ \\ ${ }^{1}$ Centre National de la Recherche Scientifique, Laboratoire de Physiologie Cérébrale, Université Paris Descartes, Paris, \\ France; and ${ }^{2}$ Unit of Anatomy, Department of Medicine, University of Fribourg, Fribourg, Switzerland
}

Submitted 16 February 2011; accepted in final form 30 June 2011

Franconville R, Revet G, Astorga G, Schwaller B, Llano I. Somatic calcium level reports integrated spiking activity of cerebellar interneurons in vitro and in vivo. J Neurophysiol 106: 1793-1805, 2011. First published July 6, 2011; doi:10.1152/jn.00133.2011.-We examined the relationship between somatic $\mathrm{Ca}^{2+}$ signals and spiking activity of cerebellar molecular layer interneurons (MLIs) in adult mice. Using two-photon microscopy in conjunction with cell-attached recordings in slices, we show that in tonically firing MLIs loaded with high-affinity $\mathrm{Ca}^{2+}$ probes, $\mathrm{Ca}^{2+}$-dependent fluorescence transients are absent. Spike-triggered averages of fluorescence traces for MLIs spiking at low rates revealed that the fluorescence change associated with an action potential is small (1\% of the basal fluorescence). To uncover the relationship between intracellular $\mathrm{Ca}^{2+}$ concentration $\left(\left[\mathrm{Ca}^{2+}\right]_{\mathrm{i}}\right.$ ) and firing rates, spikes were transiently silenced with puffs of the $\mathrm{GABA}_{\mathrm{A}}$ receptor agonist muscimol. $\left[\mathrm{Ca}^{2+}\right]_{\mathrm{i}}$ relaxed toward basal levels following a single exponential whose amplitude correlated to the preceding spike frequency. The relaxation time constant was slow (2.5 s) and independent of the probe concentration. Data from parvalbumin $(\mathrm{PV})-/-$ animals indicate that $\mathrm{PV}$ controls the amplitude and decay time of spike-triggered averages as well as the time course of $\left[\mathrm{Ca}^{2+}\right]_{\mathrm{i}}$ relaxations following spike silencing. The $\left[\mathrm{Ca}^{2+}\right]_{i}$ signals were sensitive to the L-type $\mathrm{Ca}^{2+}$ channel blocker nimodipine and insensitive to ryanodine. In anesthetized mice, as in slices, fluorescence traces from most MLIs did not show spontaneous transients. They nonetheless responded to muscimol iontophoresis with relaxations similar to those obtained in vitro, suggesting a state of tonic firing with estimated spiking rates ranging from 2 to $30 \mathrm{~Hz}$. Altogether, the $\left[\mathrm{Ca}^{2+}\right]_{\mathrm{i}}$ signal appears to reflect the integral of the spiking activity in MLIs. We propose that the muscimol silencing strategy can be extended to other tonically spiking neurons with similar $\left[\mathrm{Ca}^{2+}\right]_{\mathrm{i}}$ homeostasis.

calcium imaging; firing rate; cerebellum; parvalbumin

IN THE PAST DECADE, somatic intracellular $\mathrm{Ca}^{2+}$ concentration $\left(\left[\mathrm{Ca}^{2+}\right]_{\mathrm{i}}\right)$ signals have become a method of choice for investigating electrical activity in neuronal networks in vitro as well as in vivo (Garaschuk et al. 2006a; Grewe and Helmchen 2009). A key reason behind this success is that the elementary signal, namely, the change in fluorescence associated with a single action potential, is quite robust: peak amplitudes of $10 \%$ per spike are commonly reported by high-affinity organic $\mathrm{Ca}^{2+}$ indicators. A recent in vivo study in the mouse visual cortex indicates, however, that such robust signals do not occur in all mammalian neurons. This study found that spike-evoked fluorescence transients in the soma of cortical inhibitory interneurons are quite small $(<1 \%)$, whereas excitatory neurons in the

Address for reprint requests and other correspondence: I. Llano, Laboratoire de Physiologie Cérébrale, Univ. Paris Descartes, 45 rue des Saints Pères, Paris 75006, France (e-mail: isabel.1lano@parisdescartes.fr). same preparation display transients with peak amplitudes in the $10 \%$ range (Kerlin et al. 2010).

Earlier work from our laboratory carried out in slices from juvenile rats and under whole cell recording (WCR) conditions likewise indicates that in cerebellar molecular layer interneurons (MLIs) depolarization evokes strong $\left[\mathrm{Ca}^{2+}\right]_{i}$ rises in axonal varicosities but not in the somatodendritic compartment (Llano et al. 1997). It therefore seems plausible that the small size of spike-induced somatic $\left[\mathrm{Ca}^{2+}\right]_{i}$ rises is a common feature of inhibitory neurons. The finding that stellate cells in the turtle cerebellum have weak voltage-gated somatodendritic conductances (Midtgaard 1992) is in accord with such a postulate. The aim of the present work was to analyze spikerelated somatic $\left[\mathrm{Ca}^{2+}\right]_{i}$ signals in unperturbed adult MLIs under in vitro and in vivo conditions. To this end, we monitored somatic $\left[\mathrm{Ca}^{2+}\right]_{\mathrm{i}}$ signals, using two-photon laser scanning microscopy (2PLSM), from MLIs loaded with cell-permeant $\mathrm{Ca}^{2+}$ fluorescent probes. Combining cell-attached recordings with 2PLSM in vitro, we analyzed the fluorescence patterns during spontaneous firing and showed that indeed somatic $\left[\mathrm{Ca}^{2+}\right]_{\mathrm{i}}$ transients induced by single spikes are quite small. We therefore developed a strategy to assess spike rates by analyzing the fluorescence relaxations following spike silencing by short exposures to muscimol. Moreover, we show that the $\mathrm{Ca}^{2+}$-binding protein parvalbumin (PV) is important in the regulation of the amplitude and time course of spike-induced $\left[\mathrm{Ca}^{2+}\right]_{\mathrm{i}}$ signals. Altogether the results suggest that in MLIs the somatic $\left[\mathrm{Ca}^{2+}\right]_{\mathrm{i}}$ is not a direct readout of the firing activity, but rather reflects the time integral of this activity.

\section{MATERIALS AND METHODS}

All experimental procedures were designed in accordance with the animal care guidelines of our host institution, which have been approved by the "Prefecture de Police" (approval number A-750607) following inspection by Veterinary Services of the City of Paris and by representatives of the French Ministry of Research and the Ministry for Health, in agreement with European Directive 86/609/EEC regarding the protection of animals used for experimental and other scientific purposes.

\section{In Vitro Patch-Clamp Recording and Imaging}

Slice preparation. Sagittal cerebellar slices $(200 \mu \mathrm{m}$ thick) were prepared from $\mathrm{C} 57 \mathrm{BL} / 6 \mathrm{~J}$ mice and from $\mathrm{PV}-/-$ mice. The $\mathrm{PV}-/-$ animals are congenic with C57BL/6J, after 10 matings of heterozygous (PV+/-) mice with wild-type C57BL/6J animals (Moreno et al 2011). Mice aged 22-33 days were decapitated after cervical dislocation. Slices were cut at $4{ }^{\circ} \mathrm{C}$ in a saline solution of the following composition (in mM): $87 \mathrm{NaCl}, 2.5 \mathrm{KCl}, 1.25 \mathrm{NaH}_{2} \mathrm{PO}_{4}, 25 \mathrm{NaHCO}_{3}$, 
$0.5 \mathrm{CaCl}_{2}, 7 \mathrm{MgCl}_{2}, 10$ glucose, and 75 sucrose. The NMDA receptor antagonist D-(-)-2-amino-5-phosphonopentanoic acid (D-APV) was added to the solution at a concentration of $50 \mu \mathrm{M}$. This saline solution is based on that used to prepare slices optimized for recording from presynaptic buttons in hippocampal slices (Engel and Jonas 2005). We found that MLI survival on the superficial layers of slices from adult mice was much improved by the use of this saline solution, thus aiding the $\mathrm{Ca}^{2+}$ indicator loading procedure, which targets mainly superficial cells. The slices were maintained in sucrose saline at $34^{\circ} \mathrm{C}$ for $30-40$ min and subsequently transferred to a standard extracellular saline solution (hereafter called BBS) containing (in $\mathrm{mM}$ ) $125 \mathrm{NaCl}, 2.5$ $\mathrm{KCl}, 1.25 \mathrm{NaH}_{2} \mathrm{PO}_{4}, 25 \mathrm{NaHCO}_{3}, 2 \mathrm{CaCl}_{2}, 1 \mathrm{MgCl}_{2}$, and 10 glucose. Both solutions have a $\mathrm{pH}$ of 7.3 when equilibrated with a $95 \% \mathrm{O}_{2}-5 \%$ $\mathrm{CO}_{2}$ mixture (hereafter called carbogen).

Acetoxymethyl ester bath loading. Stocks of the acetoxymethyl esters (AM) of the fluorescent $\mathrm{Ca}^{2+}$ indicators fura- 2 and Oregon Green 488 BAPTA-1 (OGB-1) were prepared at a concentration of 5 $\mathrm{mM}$ according to a procedure (Ikegaya et al. 2005) similar to that described for bulk loading of AM indicators (Garaschuk et al. 2006b). The contents of a 50- $\mu \mathrm{g}$ vial (Invitrogen Europe) were dissolved in 10 $\mu \mathrm{l}$ of a mixture of DMSO with 10\% Pluronic F-127 (Invitrogen Europe) and $0.5 \%$ Cremophor-EL (Sigma Europe). In accord with a report analyzing loading of AM indicators in slices from various brain regions (Namiki et al. 2009), the combination of the two solubilizing agents proved quite efficient for loading the AM probes into MLIs of adult mice. At the time of loading, the stock was diluted in BBS to final concentrations of $2 \mu \mathrm{M}$ for fura-2 AM and $25 \mu \mathrm{M}$ for OGB-1 $\mathrm{AM}$, with care taken to preheat the BBS solution to $34^{\circ} \mathrm{C}$. These concentrations yielded comparable intracellular levels of the indicators. A slice was transferred to a small beaker with $2 \mathrm{ml}$ of dyecontaining BBS and was maintained in the loading solution at $34^{\circ} \mathrm{C}$ for $40 \mathrm{~min}$. Carbogen was puffed onto the surface of the solution, and the beaker was sealed to keep a correct $\mathrm{pH}$ value and a high $\mathrm{O}_{2}$ content.

MLI $\left[\mathrm{Ca}^{2+}\right]_{i}$ imaging and spike recordings. At the end of the loading period slices were transferred to the recording setup, where the bath was continuously perfused at a rate of $1.5 \mathrm{ml} / \mathrm{min}$ with BBS. When experiments were performed at near-physiological temperature, the bath was set to $34-35^{\circ} \mathrm{C}$ by means of a Peltier element and temperature was monitored with a calibrated thermistor. The cellattached configuration of the patch-clamp technique was used to record the capacitive currents associated with action potentials. For these recordings, pipettes were filled with a HEPES-buffered saline (HBS) of the following composition (in $\mathrm{mM}$ ): $145 \mathrm{NaCl}, 2.5 \mathrm{KCl}, 2$ $\mathrm{CaCl}_{2}, 1 \mathrm{MgCl}_{2}$, and 10 HEPES-Na ( $\mathrm{pH} \mathrm{7.3)} \mathrm{and} \mathrm{had} \mathrm{a} \mathrm{resistance} \mathrm{of}$ 7-9 M $\Omega$. An EPC-10 amplifier (HEKA Elektronik) was used for acquisition and electrical control. Recordings were performed while the patch was maintained at $0 \mathrm{mV}$. Seal resistances ranged from 40 $\mathrm{M} \Omega$ to $>4 \mathrm{G} \Omega$. We did not detect any influence of the seal resistance value on the parameters analyzed in the present work. Therefore, results from so-called "loose seal" recordings have been pooled together with those from "G $\Omega$ seal" recordings.

To monitor fluorescence from somata of AM-loaded MLIs we used a homemade 2PLSM setup that has been described in detail elsewhere (Tan et al. 1999; Collin et al. 2005). The excitation wavelength of the MaiTai laser (Spectra Physics) was set at $810 \mathrm{~nm}$ because this wavelength is optimal for fura-2 imaging in 2PLSM (Wokosin et al. 2004). Scan protocols had dwell times of 10-24 ms and consisted of a series of scans with no interval between successive scans. The total time recorded for each series of scans (and thus the total time of illumination) was between 20 and $60 \mathrm{~s}$. Care was taken to keep the average excitation power below $6 \mathrm{~mW}$ at the objective pupil, in order to avoid photodamage.

MLI silencing. To stop MLI firing, we used the $\mathrm{GABA}_{\mathrm{A}}$ agonist muscimol at a concentration of $1 \mu \mathrm{M}$. Two-second puffs of the agonist were applied with a puffer pipette placed 20-30 $\mu \mathrm{m}$ from the MLI soma and filled with HBS. The pipette had a tip opening of $\sim 2$ $\mu \mathrm{m}$ and was connected to a Picospritzer (General Valve) set at 5-7 psi. Fluorescence movies were visually inspected for movement artifacts, and runs in which the puff generated a movement of the cell were discarded from analysis.

Preloading fura-2. In a subset of experiments, we introduced the $\mathrm{K}^{+}$salt of fura- 2 into MLI somata by a preloading technique described previously (Conti et al. 2004). WCR was performed with pipettes filled with a solution containing (in $\mathrm{mM}$ ) $140 \mathrm{~K}$ gluconate, 5.4 $\mathrm{KCl}, 4.1 \mathrm{MgCl}_{2}$, 9.9 HEPES-K, 0.36 Na-GTP, 3.6 Na-ATP, and 0.1 fura-2. The WCR was kept for $30-50 \mathrm{~s}$, and the pipette was then removed gently to obtain a tight outside-out patch. A new pipette filled with HBS was used for the cell-attached recording, as in AM-loading experiments.

\section{In Vivo Imaging}

Anesthesia and monitoring. After a light dose of isoflurane administered by inhalation, C57BL/6 female mice aged 25-50 days were anesthetized by intraperitoneal injection of a mixture of ketamine (75 $\mathrm{mg} / \mathrm{kg}$ ) and xylazine $(10 \mathrm{mg} / \mathrm{kg})$. The volume injected was $400 \mu \mathrm{l}$ for a 20-g mouse. A rectal temperature probe was then inserted, and the animal was kept on a heated blanket whose temperature was adjusted to ensure a reading of $37^{\circ} \mathrm{C}$ (FHC temperature control unit). A pulse oximeter probe (MouseOx Pulse Oximeter; Starr Life Sciences) was placed on the hind leg, and the parameters reported by the system (partial $\mathrm{O}_{2}$ pressure, heart rate, and breathing rate) were monitored continuously throughout surgery and imaging. Animals were provided a mixture of $80 \%$ air and $20 \% \mathrm{O}_{2}$ through a nasal mask. We found that animals that were allowed to breathe air without $\mathrm{O}_{2}$ supplement were hypoxic, the partial pressure of $\mathrm{O}_{2}$ being as low as $80 \%$. Anesthesia was maintained with ketamine-xylazine at one-eighth to one-fourth of the induction dose given every $20 \mathrm{~min}$ through an intraperitoneal catheter. Anesthesia was assessed by the lack of pinch withdrawal and the absence of whisker movements. Doses were adjusted to maintain the partial pressure of $\mathrm{O}_{2}$ above $95 \%$ and keep the heart rate stable.

Surgery. The skin overlying the frontal, parietal, and interparietal bones was removed, and the head of the mouse was immobilized by gluing a homemade aluminum bar to the cleaned skull with dental cement. The bar was usually attached close to the fronto-parietal junction and was also used to maintain the head at the correct angle for visualization of the cerebellar cortex. A small pool with dental cement walls was constructed and filled with prewarmed HBS. The animal was transferred to the imaging setup after a small craniotomy was drilled in the parietal bone (hole diameter $0.5-1.0 \mathrm{~mm}$ ) over the region covering lobule 4 or 5 of the cerebellar vermis (Ideal MicroDrill, CellPoint Scientific; 0.5-mm carbon burr, FST).

AM bolus loading. Bulk loading of fura-2 AM or OGB-1 AM followed procedures similar to those previously described (Garaschuk et al. 2006b; Stosiek et al. 2003). A $10 \mathrm{mM}$ stock solution of the probe was prepared in DMSO-10\% Pluronic and diluted to $500 \mu \mathrm{M}$ with HBS just prior to the experiment. Patch pipettes, of a resistance close to $10 \mathrm{M} \Omega$ when filled with HBS, were beveled to $4-7 \mathrm{M} \Omega$ in order to improve tissue penetration and introduced into the cerebellar cortex at an angle of $50^{\circ}$ under 10 -fold magnification. Pipette advance was guided by visual inspection of the reflected light images with a CCD camera. The pipettes were connected to a patch-clamp amplifier to monitor pipette resistance and to a Picospritzer used to pressure inject the indicator once the desired level in the cerebellar molecular layer was reached. At this location, extracellular spike activity was often seen by the amplifier connected to the pipette. Injection pressure varied between 0.8 and 3 psi and lasted $2-8$ min. Imaging started $\sim 1$ $\mathrm{h}$ after $\mathrm{AM}$ injection. In two experiments the multidrug resistance transporter blocker MK-571 was added to the bolus loading solution at a concentration of $200 \mu \mathrm{M}$. We found that this improved Purkinje cell staining in accord with published effects of this drug on the loading of AM dyes in Xenopus brain slices (Manzini et al. 2008). 
In vivo $\left[\mathrm{Ca}^{2+}\right]_{i}$ imaging. In the imaging setup the animal was placed on a motorized platform under software control. The twophoton excitation was supplied by a MaiTai laser set at $810 \mathrm{~nm}$. A Pockels cell (Conoptics) inserted in the excitation path served as fast shutter and allowed modulation of the excitation power. Average power out of the objective ranged from 2 to $20 \mathrm{~mW}$. Scanning was performed with galvanometers carrying 4-mm mirrors (VM500 scanners; Cambridge Technology) and with scanning procedures based on those described previously (Tan et al. 1999). Light was focused by a water immersion lens with 20-fold magnification (NA 0.95, Olympus), which ensured a large acceptance angle over a large field of view and, because of its large back aperture, required an expansion of the laser beam. The total beam expansion (factor: 7.2) was a compromise between the need to fill the objective back pupil and the loss of laser power. The detection path was designed to optimize photon collection in depth through proximal detection (Oheim et al. 2001). The emitted light passed by a large dichroic mirror (50-mm diameter, 670DCXXR; Chroma Technology) was recovered by a 50-mm-diameter aspheric lens with focal distance appropriate to focus photons on the 5-mm surface of a closely placed photomultiplier tube (H7422P-40 MOD; Hamamatsu). Photons were counted by a photon counting module whose output was passed through a Bessel filter before being digitized via an A/D interface (ITC-18; Instrutech) that also served to command the galvanometers with routines written in IgorPro (Wavemetrics).

Scanning of large fields $(600 \times 300 \mu \mathrm{m})$ was used to identify structures and was performed at an effective pixel size of $0.5 \mu \mathrm{m}$. For imaging individual MLIs or small groups of five to eight MLIs with a temporal resolution in the millisecond range we implemented the targeted path scanning strategy (TPS; Lillis et al. 2008), in which the laser beam follows an optimized trajectory passing through the structures of interest. TPS protocols covered fields of $\sim 200 \times 200 \mu \mathrm{m}$ with a total frame time of $10-16 \mathrm{~ms}$ and a dwell time per MLI of $1-2$ ms. To monitor single MLIs, smaller fields (10-20 $\mu \mathrm{m}$ wide) were scanned at an effective pixel size of $0.25 \mu \mathrm{m}$ and dwell times of $30-60 \mathrm{~ms}$.

Extracellular electrical stimulation consisted of $10-\mathrm{Hz}$ trains of pulses (400- $\mu$ s duration; 2- to $10-\mu \mathrm{A}$ amplitude) delivered between two platinum electrodes by an isolated pulse stimulator (A-M Systems). One electrode was immersed in the saline bathing the skull, and the other was placed inside a glass pipette filled with HBS. Pipettes had resistances of 5-7 M $\Omega$ and were placed within $150 \mu \mathrm{m}$ from the MLIs studied.

For iontophoretic applications of muscimol in vivo, glass pipettes (tip size 1-2 $\mu \mathrm{m}$ ) were filled with a solution of $0.5 \mathrm{mM}$ muscimol diluted in water ( $\mathrm{pH}$ adjusted to 3.0 with $\mathrm{HCl}$ ). Iontophoretic applications consisted of 2-s-long pulses of 100-nA current applied from a battery-operated unit (Bionic Instruments) between the glass pipette and a reference electrode placed similarly to that used for extracellular stimulation. A 10-nA negative retaining current was applied throughout the experiment to prevent leaking of muscimol from the pipette tip. To aid pipette visualization in the tissue, Texas Red dextran mol wt 3,000 was added to the pipette solution at $8 \mathrm{mM}$.

\section{Analysis Procedures}

Automatic region of interest detection and estimates of fluorescence changes. Somas were detected on average images with a $\mathrm{K}$-means clustering algorithm. The statistical procedure for estimating background values was a modified version of that proposed by Chen et al. (2006). This procedure yields, for a sequence of images, the mean background-subtracted fluorescence $(\mathrm{F})$ in the region of interest (ROI) as a function of time $[\mathrm{F}(t)]$. Analysis of the changes in fluorescence associated with pauses in action potential firing induced by muscimol were performed by fitting a single exponential function to the relaxation phase of $\mathrm{F}(t)$. The time of the fit was defined as the period in which no action potentials occurred. The estimated parameters were the time constant $(\tau)$, the resting fluorescence $\left(\mathrm{F}_{\mathrm{bsl}}\right)$ and the absolute amplitude of the fluorescence change relative to the baseline $\left(\Delta \mathrm{F} / \mathrm{F}_{\mathrm{bsl}}\right)$ defined as $\mathrm{l}\left(\mathrm{F}-\mathrm{F}_{\mathrm{bsl}}\right) / \mathrm{F}_{\mathrm{bsl}} \mathrm{l}$.

Spike detection and spike-triggered averaging. Spikes were detected as local maxima on the current trace, with 1-ms windows and a manually fixed threshold. Spike rates were calculated by convolving the spike trains with a Gaussian kernel of width 4 times the median of the interspike intervals of the train. To estimate the fluorescence fluctuations related to single spikes, fluorescence sweeps centered on the spikes were produced from the average of those sweeps in which no other spikes were detected in the $200 \mathrm{~ms}$ preceding and the $200 \mathrm{~ms}$ following the spike. This window is a compromise between the need to limit contamination due to spikes flanking the central signal and the need to average over a sufficient number of spikes because of the small unitary signal size. In PV $-/-$ data, decay of spike-triggered averaged signals was about sevenfold slower than in data from wild-type animals (see Fig. 4A). Therefore a longer time was required to allow for accurate estimate of the decay rate. For this reason, average sweeps were produced from sweeps in which no spikes were detected in the $500 \mathrm{~ms}$ preceding and the $2 \mathrm{~s}$ following the spike.

Estimating fura-2 concentration. WCR experiments were carried out on MLIs in vitro with the $\mathrm{K}^{+}$gluconate-based intracellular solution described above, to which the $\mathrm{K}^{+}$salt of fura- 2 was added at concentrations of $10-100 \mu \mathrm{M}$. Images of the soma were acquired at regular intervals with the cell clamped at $-70 \mathrm{mV}$. Once the photon counts reached a stable level, they were normalized to the photon counts recorded daily from a solution of $50 \mu \mathrm{M}$ fluorescein prior to the experiment. Normalization was done after appropriate correction of the excitation power at the objective pupil. Normalized photon counts from 11 MLIs were plotted as a function of the fura-2 concentration in the pipette, and a straight line was adjusted to the data to obtain the best estimate for the slope. This value was used to convert normalized photon counts in AM loading and pipette preloading experiments to fura- 2 concentration.

\section{Statistical Procedures}

Statistical values are given as means \pm SE. Student's $t$-tests or Welch's $t$-tests were used to evaluate statistical differences. Results were considered significantly different if $P \leq 0.05$. For statistics on time constants of decay $\tau$ of muscimol-induced transients, runs in which the SD of the $\tau$ estimated by the fitting procedure was $>0.5 \mathrm{~s}$ were eliminated from the data pool. When reporting on correlations we use the Pearson's $r$ statistic.

\section{RESULTS}

\section{Somatic $\left[\mathrm{Ca}^{2+}\right]_{i}$ Signals from MLIs in Vitro}

To characterize the $\mathrm{Ca}^{2+}$-dependent fluorescence signals associated with MLI firing, cerebellar slices from adult mice were loaded with fura-2 AM or OGB-1 AM. With both indicators the loading resulted in clearly recognizable somata in the molecular layer (example for fura-2 in Fig. 1A).

To explore the spontaneous excitability of MLIs we performed cell-attached recordings while imaging the corresponding somata. Virtually all cells examined in this manner were found to fire action potentials in accord with previous studies showing that in cerebellar slices Purkinje cells (Llinás and Sugimori 1980a; Häusser and Clark 1997; Womack and Khodakhah 2002) as well as MLIs (Llano and Gerschenfeld 1993; Häusser and Clark 1997) are spontaneously active. Since MLIs are the only neurons having their somata in the molecular layer, the identification was unambiguous.

Firing frequencies displayed significant cell-to-cell variations, both at room temperature and at near-physiological 
Fig. 1. Different modes of spiking in molecular layer interneurons (MLIs). A: maximumintensity projection of 11 two-photon laser scanning microscopy (2PLSM) images taken at different focal planes (1- $\mu \mathrm{m}$ intervals) in a $60 \times 60-\mu \mathrm{m}$ field of the cerebellar molecular layer of a slice loaded with fura-2 AM. B, top: simultaneous fluorescence and electrophysiological recordings from a MLI in a cerebellar slice loaded with fura-2 AM. Below the trace each vertical line indicates the position in time of the individual spikes recorded in the cell-attached configuration. The pronounced bursting in the electrical trace is paralleled by fluctuations in the fluorescence trace. In this and following figures, fluorescence was quantified in the region delimited by the white contour shown on the images at left. Bottom: spike rate calculated for the spike trace at top. $C$ : simultaneous fluorescence and electrophysiological recordings from another fura-2loaded MLI with a regular spiking activity. The time bar in $C$ holds also for $B$.

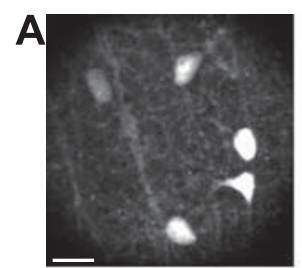

$10 \mu \mathrm{m}$
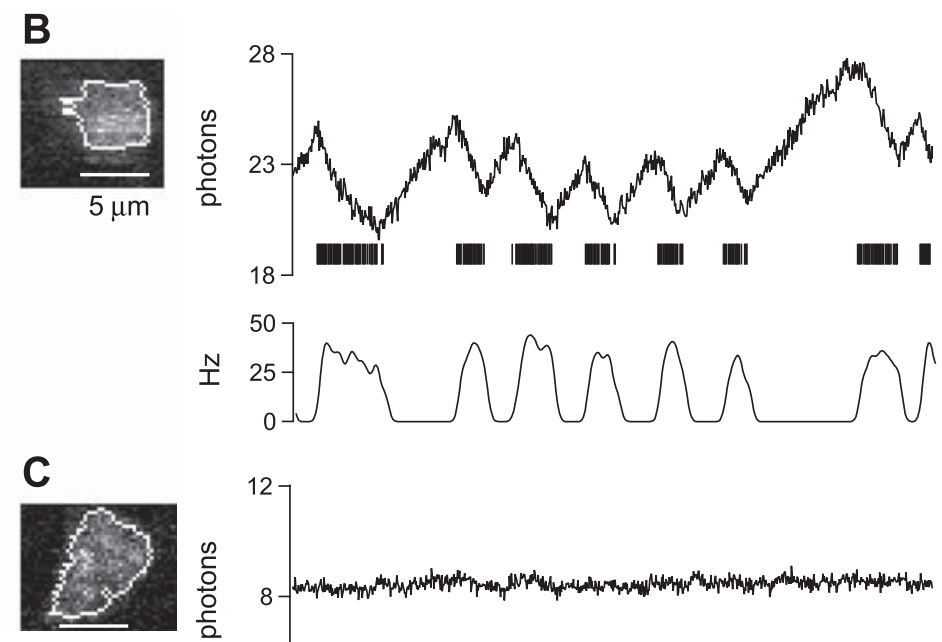

$5 \mu \mathrm{m}$
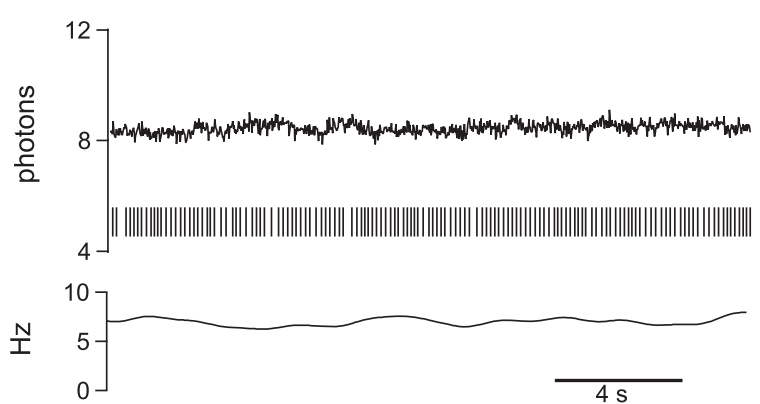

temperature $\left(34^{\circ} \mathrm{C}\right)$; mean values obtained within 4 min after the cell-attached configuration was established were significantly higher at $34^{\circ} \mathrm{C}(13.3 \pm 2.1 \mathrm{~Hz} ; n=10)$ than at room temperature $(6.9 \pm 1.4 \mathrm{~Hz} ; n=19)$ (Welch's $t$-test $P=0.01)$.

The pattern of action potential occurrences was variable, ranging from intermittent bursts of spikes to regular firing. In bursting cells, the $\mathrm{Ca}^{2+}$-dependent fluorescence signals displayed a jagged pattern, with slope changes associated with the onset and end of the spike bursts (example in Fig. 1B). On the other hand, in cases where the action potentials occurred regularly there were no detectable fluctuations in the associated fluorescence trace (example in Fig. 1C). The lack of clear fluctuations in regular spiking MLIs was a common feature of fura-2- and OGB-1-loaded MLIs, and it was independent of firing rate. Fluctuations were absent even when firing frequencies were lower than $5 \mathrm{~Hz}$, a frequency range where conditions should be favorable for detecting unitary spike-related fluorescence signals because there is sufficient time between individual spikes for the fluorescence to return to its resting value (example for an OGB-1-loaded MLI in Fig. 2A).

Changes in fluorescence associated with single action potentials could nevertheless be estimated in MLIs that fired tonically at rates below $5 \mathrm{~Hz}$ by performing spike-triggered averages of the fluorescence trace (see MATERIALS AND METHODS). The resulting signals were quite small. These unitary signals had a mean peak amplitude of $1.05 \pm 0.29 \%$ in MLIs loaded with fura-2 $(n=8$; average trace in Fig. $2 B)$ and $1.8 \% \pm 0.22 \%$ in MLIs loaded with OGB-1 $(n=5$; average trace in Fig. 2C).

These results show that the somatic $\left[\mathrm{Ca}^{2+}\right]_{\mathrm{i}}$ rises evoked by single action potentials in adult MLIs are small, their peak amplitudes being comparable to those recently found in cortical inhibitory neurons (Kerlin et al. 2010). The lack of fluctuations in the fluorescence traces of regularly firing MLIs stands in sharp contrast to results from hippocampal and cortical neurons, where experimental paradigms similar to those used here (i.e., simultaneous cell-attached and fluorescence recordings) reveal that action potentials are associated with well-

defined transients (size on the order of $10 \%$ per action potential) in the fluorescence reported by high-affinity $\mathrm{Ca}^{2+}$ indicators both in vitro (Mao et al. 2001) and in vivo (examples in Kerr et al. 2005; Rothschild et al. 2010; Sato et al. 2007).

\section{Relation Between Firing Rate and Fluorescence}

The data of Figs. 1 and 2 indicate that, as a rule, somatic $\mathrm{Ca}^{2+}$-dependent fluorescence signals reported by fura- 2 or OGB-1 cannot be used to detect single action potentials from MLIs. The slow changes observed in bursting cells (Fig. 1B) suggest that the fluorescence level depends not only on the present activity of the cell but also on the previous firing history. It is clear in such a record that the pauses in spike firing

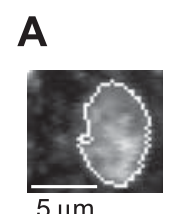

$5 \mu \mathrm{m}$

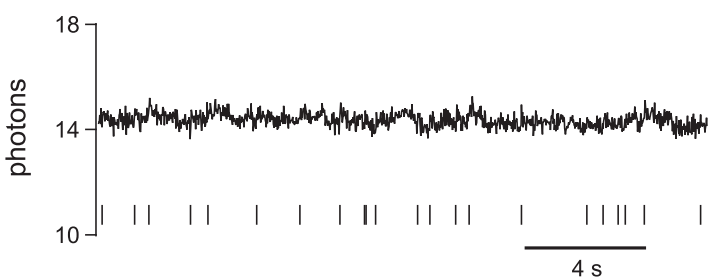

B

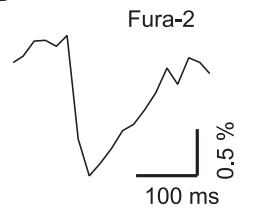

c

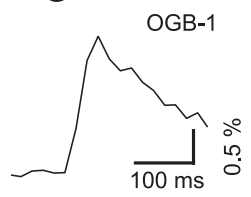

Fig. 2. A: simultaneous fluorescence and electrophysiological recordings from an Oregon Green 488 BAPTA-1 (OGB-1)-loaded MLI spiking at an average rate of $0.7 \mathrm{~Hz}$. B: average trace obtained from spike-triggered averages of spontaneous fluorescence fluctuations in 8 sparsely spiking MLIs loaded with fura-2. $C$ : average trace obtained from spike-triggered averages of spontaneous fluorescence fluctuations in 5 sparsely spiking MLIs loaded with OGB-1. Cells were used for $B$ or $C$ only if the firing rate was below $5 \mathrm{~Hz}$. Spike-triggered averages of individual cells were first constructed from traces in which no firing occurred in the $200 \mathrm{~ms}$ preceding and the $200 \mathrm{~ms}$ following the spike. These averages were then pooled together to yield the traces displayed. 
are not long enough for the fluorescence to return to its resting state. The lack of fluctuations in tonically firing cells (Figs. $1 C$ and $2 A$ ) is therefore likely to result from the fact that the fluorescence is in a dynamic steady state that depends on the recent firing history of the cell. Determining the true resting fluorescence is, however, a prerequisite to relating the calcium signal to the spiking rate.

To determine this resting level we resorted to silencing MLIs with local puff applications of the $\mathrm{GABA}_{\mathrm{A}}$ receptor agonist muscimol. Experiments were conducted in MLIs loaded with fura- 2 because when bulk AM loading was done in vivo, fura-2 yielded a more favorable staining for MLIs than OGB-1 (see below). When used at $1 \mu \mathrm{M}, 2$-s-long muscimol puffs resulted in an immediate silencing of the MLIs that lasted for 5-30 s (Fig. 3A). During the silent period the fluorescence increased, indicating a $\left[\mathrm{Ca}^{2+}\right]_{\mathrm{i}}$ decrease, and the corresponding fluorescence variation could be well approximated with a monoexponential whose asymptote was taken as the basal level fluorescence, hereafter called $\mathrm{F}_{\mathrm{bsl}}$. We therefore calculated the level of fluorescence immediately prior to the puff relative to the ground level $\left(\Delta \mathrm{F} / \mathrm{F}_{\mathrm{bsl}}\right)$. As seen in the plots of Fig. 3, this variable was correlated across trials to the spiking frequency in the 1-s period preceding the puff both at room temperature (Fig. $3 B ; r=0.661, P=2 \times 10^{-9}$ ) and at $34^{\circ} \mathrm{C}$ (Fig. $3 C ; r=$ $0.749, P=4 \times 10^{-8}$ ). These plots can be viewed as an approximation of the level of fluorescence at equilibrium as a function of the spike frequency (i.e., the stable level of fluorescence attained after a sustained period of firing at a given firing rate). We verified that the parameters obtained were within $1 \%$ of those returned from the fits when a 5-s window was used to estimate the spike rate, indicating that we are indeed dealing with stable firing rates.

Previous work in which fura-2 was used to study action potential-evoked $\left[\mathrm{Ca}^{2+}\right]_{\mathrm{i}}$ signals in dendrites of cortical layer $\mathrm{V}$ pyramidal neurons yielded a linear relation between spike frequency and plateau $\left[\mathrm{Ca}^{2+}\right]_{\mathrm{i}}$, suggesting linear summation of spike-related $\left[\mathrm{Ca}^{2+}\right]_{\mathrm{i}}$ signals (Helmchen et al. 1996). In the present study, the experimental design was different: we assessed the recovery of $\left[\mathrm{Ca}^{2+}\right]_{\mathrm{i}}$ from a dynamic steady state, set by the cell's firing frequency. At room temperature (Fig. 3B) we obtained a relation between spike rates and $\Delta \mathrm{F} / \mathrm{F}_{\mathrm{bsl}}$ that was close to linear for frequencies below $20 \mathrm{~Hz}$, but at $34^{\circ} \mathrm{C}$ (Fig. $3 C$ ) the relation displayed a clear plateau at high firing frequencies. $\mathrm{Ca}^{2+}$ extrusion from low to intermediate $\left[\mathrm{Ca}^{2+}\right]_{\mathrm{i}}$ levels is assumed to be mediated mainly by high-affinity, low-capacity $\mathrm{Ca}^{2+}$-ATPases, e.g., the plasma membrane $\mathrm{Ca}^{2+}$ pumps (PMCA), that show a nonlinear relation between $\left[\mathrm{Ca}^{2+}\right]_{\mathrm{i}}$ and extrusion rates (Brini and Carafoli 2011). Furthermore, the activity of these $\mathrm{Ca}^{2+}$-ATPases shows a strong temperature dependence (high $\mathrm{Q}_{10}$ ). Therefore, a likely explanation for the results is that at higher temperatures and at higher $\left[\mathrm{Ca}^{2+}\right]_{\mathrm{i}}$ levels $\mathrm{Ca}^{2+}$ extrusion systems (notably $\mathrm{Ca}^{2+}$ -

\section{A}

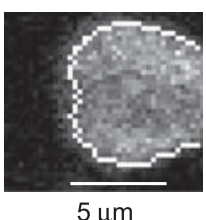

$5 \mu \mathrm{m}$

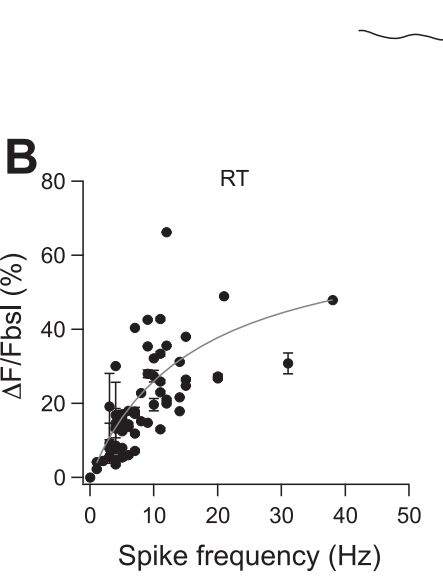

$1 \mu \mathrm{M}$ Muscimol

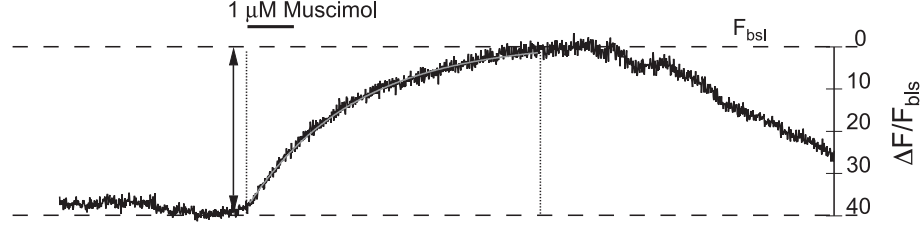

| | || ||||||| | ||||||||||||||||||||||||||||||||||

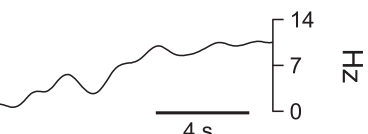

c

$34^{\circ} \mathrm{C}$

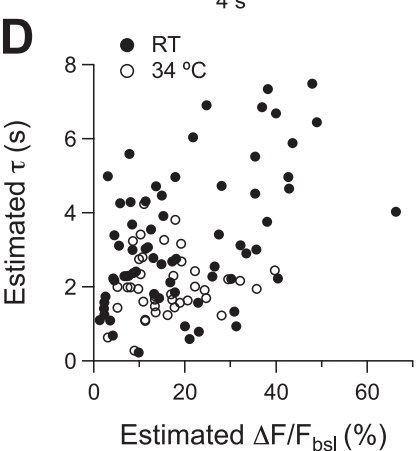

Fig. 3. Silencing spikes with muscimol. A, top: increases in fluorescence induced by a 2-s puff of $1 \mu \mathrm{M}$ muscimol to the soma of a MLI, at the time indicated by the bar above the trace. Fluorescence was quantified in the region delimited by the contour shown on the image at left. The solid gray line superimposed on the fluorescence trace corresponds to the fit of the data points to a single exponential function during the pause in spiking, as indicated by the dashed vertical lines. The time constant from this fit was $4.5 \mathrm{~s}$. The vertical lines below the fluorescence trace denote the time of individual spikes from the cell-attached recording, and the plot at bottom reports the instantaneous firing frequency. $\Delta \mathrm{F} / \mathrm{F}_{\mathrm{bsl}}$, fluorescence change relative to baseline. $B$ : plots of estimates of the muscimol-induced changes in fluorescence against spike frequency during the second preceding the puff at room temperature (RT); data from 24 cells. Each circle corresponds to the mean value for the fluorescence estimate, while the bars denote the SD of the estimate. Note that many bars are smaller than the dots. The solid gray line displays the fit of the data to a hyperbolic function, $Y=\left(Y_{\max } \times X\right) /\left(X+X_{1 / 2}\right)$, where $Y_{\max }$ corresponds to the saturating value for $\Delta \mathrm{F} / \mathrm{F}_{\mathrm{bsl}}$ and $X_{1 / 2}$ to the spike frequency at the midpoint of the relation. Fit parameters $\left( \pm 95 \%\right.$ confidence interval) are $Y_{\max }=68.4 \pm 0.33 \%, X_{1 / 2}=16.2 \pm 0.17 \mathrm{~Hz}$. $C$ : same plot as in $B$, but from 12 MLIs studied at $34^{\circ} \mathrm{C}$. Parameters from the hyperbolic fit are $Y_{\max }=28 \pm 0.47 \%, X_{1 / 2}=6.3 \pm 0.27 \mathrm{~Hz}$. For the fits, values were weighted according to their SD. $D$ : plots of the time constants obtained from the fit of single exponential functions to the muscimol-induced change in fluorescence against the change in fluorescence relative to the baseline estimate. Filled circles denote MLIs studied at room temperature, empty circles MLIs studied at $34^{\circ} \mathrm{C}$. 
ATPases) are more active and thus more efficient in limiting the $\left[\mathrm{Ca}^{2+}\right]_{\mathrm{i}}$ rise. We therefore fitted these data with a hyperbolic function, corresponding to a simple binding function, in order to obtain estimates of the maximum $\Delta \mathrm{F} / \mathrm{F}_{\mathrm{bsl}}$ values as well as of the spike frequency associated with half saturation (see Fig. 3 legend). The asymptote $\Delta \mathrm{F} / \mathrm{F}_{\mathrm{bsl}}$ values are lower at physiological temperature than at room temperature; thus, at high firing frequencies, the relative change in fluorescence is about twofold lower at near-physiological temperature than the corresponding value at room temperature. Furthermore, the half-saturation frequency is lower at physiological temperature than at room temperature. This reflects the fact that, because of the higher efficiency of extrusion at physiological temperature, the maximal attainable level in $\left[\mathrm{Ca}^{2+}\right]_{\mathrm{i}}$, measured as $\Delta \mathrm{F} / \mathrm{F}_{\mathrm{bsl}}$, is reached at a lower firing frequency than in room temperature experiments. Both results are in accord with the temperatureand $\mathrm{Ca}^{2+}$ dependence of extrusion systems.

An alternative interpretation for the observed saturation would be that it reflects the $\mathrm{Ca}^{2+}$-binding properties of the dye. This does not appear likely for three reasons: 1) the smaller plateau value at $34^{\circ} \mathrm{C}$ could be explained by dye saturation only if $\left[\mathrm{Ca}^{2+}\right]_{\mathrm{i}}$ levels in the nonspiking condition were significantly higher at $34^{\circ} \mathrm{C}$ than at room temperature, whereas the known dependence of extrusion mechanisms on temperature predicts similar or smaller values at $34^{\circ} \mathrm{C}$ than at room temperature; 2) our previous results in Purkinje cells indicate $\left[\mathrm{Ca}^{2+}\right]_{\mathrm{i}}$ at rest on the order of $25 \mathrm{nM}$ (Fierro et al. 1998) such that maximum $\mathrm{Ca}^{2+}$ levels in the plots of Fig. 3, $B$ and $C$, are likely well below the $K_{\mathrm{d}}$ for fura-2; and 3) published work suggests an enhancement of $\mathrm{Ca}^{2+}$ extrusion at higher $\left[\mathrm{Ca}^{2+}\right]_{\mathrm{i}}$ due to the activation of $\mathrm{Ca}^{2+}$-dependent ATPases, both in cerebellar Purkinje cells (Fierro et al. 1998) and in hippocampal granule cells (Lee et al. 2009).

\section{The Fluorescence Signals Observed Are Related to MLI Firing}

Muscimol puffs have been shown to induce $\left[\mathrm{Ca}^{2+}\right]_{\mathrm{i}}$ rises in juvenile MLIs because of bicarbonate-driven depolarization (Chavas et al. 2004). Those $\left[\mathrm{Ca}^{2+}\right]_{i}$ rises do not reflect an increase in MLI firing because they are accompanied by a total cell silencing in firing cells and because they can be observed in the presence of TTX. In the present study we used a 20-fold lower muscimol concentration and a 100-fold shorter puff duration than in this earlier work, in order to obtain spike silencing while avoiding the osmotic effect. We verified in five cells that, in the conditions used in the present work, muscimol puffs induced no fluorescence changes when action potentials were blocked with $200 \mathrm{nM}$ TTX (data not shown).

\section{Kinetics of $\left[\mathrm{Ca}^{2+}\right]_{i}$ Relaxation}

The data presented in Fig. 3 show that the fluorescence relaxation following spike silencing by muscimol is slow. This decrease in $\left[\mathrm{Ca}^{2+}\right]_{\mathrm{i}}$ is the sum of several processes occurring simultaneously, including the clearance by systems in the plasma membrane or in organelles. Additionally, the recovery of $\left[\mathrm{Ca}^{2+}\right]_{i}$ to $\mathrm{F}_{\mathrm{bsl}}$ is slowed down by release of $\mathrm{Ca}^{2+}$ from cytosolic $\mathrm{Ca}^{2+}$ buffers such as PV (for details, see below). Averaging the results across trials and experiments revealed a mean time constant of relaxation $\tau$ of $3.26 \pm 0.22 \mathrm{~s}$ at room temperature (68 applications from 22 cells) and $2.04 \pm 0.13 \mathrm{~s}$ at physiological temperature (40 applications from 11 cells; Welch's $t$-test, $P=3 \times 10^{-6}$ ). At physiological temperature, $\tau$ values did not correlate with the amplitudes of the fluorescence changes $(r=0.08, P=0.63)$, indicating that $\tau$ is independent of $\left[\mathrm{Ca}^{2+}\right]_{\mathrm{i}}$ (Fig. $3 D$ ). A significant positive correlation between the two parameters was present at room temperature $\left(r=0.48, P=3.6 \times 10^{-5}\right)$. One of the possibilities for the observed difference in temperature dependence is a more efficient $\left[\mathrm{Ca}^{2+}\right]_{\mathrm{i}}$ extrusion at $34^{\circ} \mathrm{C}$ than at room temperature.

The return of fluorescence to resting levels after termination of spontaneous firing by muscimol silencing proceeds with a time course that is roughly 100-fold slower than that observed for the decay phase of spike-triggered averages in MLIs spiking at low rates. This striking difference cannot be ascribed to the specific effects of muscimol application on the cell conductance since spontaneous interruptions of spiking also resulted in very slow fluorescence changes in bursting cells (example in Fig. $1 B$ ). Thus $\left[\mathrm{Ca}^{2+}\right]_{\mathrm{i}}$ decay in MLI somata is a complex process that is fast after isolated action potentials and is slowed down very markedly after sustained firing.

\section{Assessing the Role of Parvalbumin}

The markedly different time courses observed for the $\left[\mathrm{Ca}^{2+}\right]_{\mathrm{i}}$ decrease following either single spikes or spike silencing by muscimol can be largely explained by the $\mathrm{Ca}^{2+}$-binding properties of PV. According to our previous analysis of action potential-evoked $\left[\mathrm{Ca}^{2+}\right]_{i}$ rises in MLI axons, PV efficiently buffers incoming $\mathrm{Ca}^{2+}$ for short spike trains and changes the monoexponential decay observed in PV-/- MLIs to a biphasic $\left[\mathrm{Ca}^{2+}\right]_{\mathrm{i}}$ decay with a fast $\tau$ value in the 50-100 ms range and a slower $\tau$ in the 1-2 s range (Collin et al. 2005). The fast component reflects the binding of $\mathrm{Ca}^{2+}$ to $\mathrm{PV}$ and the slower component the release of $\mathrm{Ca}^{2+}$ from PV $\left(K_{\text {off,Ca }} \sim 1 / \mathrm{s}\right.$; Lee et al. 2000). In the present experiments, the fast component would account for the time course of decay of the spiketriggered average $\left[\mathrm{Ca}^{2+}\right]_{\mathrm{i}}$ signals obtained in wild-type MLIs for spiking rates below $5 \mathrm{~Hz}$. The small size of these signals precluded adequate detection of the slow component, i.e., the release of $\mathrm{Ca}^{2+}$ from PV. On the other hand, for a cell that has been spiking tonically at a certain level for a sustained period, a significant proportion of the PV molecules are in the $\mathrm{Ca}^{2+}$ bound and act as a $\mathrm{Ca}^{2+}$ source, increasing the relative size of the slow component of the $\left[\mathrm{Ca}^{2+}\right]_{\mathrm{i}}$ tail (Collin et al. 2005). This is expected to contribute to a slower return of $\left[\mathrm{Ca}^{2+}\right]_{i}$ to baseline levels in muscimol-induced silencing experiments.

To test these predictions, we performed experiments in cerebellar slices from $\mathrm{PV}-/-$ mice. The average spiking frequency in this group of MLIs was $5.9 \pm 3.5 \mathrm{~Hz}$, not significantly different from that of control MLIs (Welch's $t$-test, $P=0.78$; room temperature experiments). However, the time course of the fluorescence relaxations in PV $-/-$ MLIs was drastically different from that of control MLIs. This difference pertained to both the elementary transients derived from spike-triggered averages and the relaxations toward resting fluorescence induced by muscimol silencing. The top plots in Fig. $4 A$ present the spike-triggered average from control MLIs (black trace; same data as in Fig. 2B) and from PV-/MLIs (gray trace; averaged from 4 cells). PV deletion resulted in a signal with twice the peak absolute amplitude and a much 
slower return to baseline levels: time to half-decay was $70 \mathrm{~ms}$ for the wild-type average and $560 \mathrm{~ms}$ for the PV-/- average. To estimate the rate of decay from these traces, the data were normalized to a peak amplitude of 1 in both cases and a linear fit was performed in a time window ranging from the peak to the time at which the fluorescence had a value equal to half the peak value. The initial rate of decay obtained in this manner was sevenfold faster for the control trace $\left(5.65 \mathrm{~s}^{-1}\right)$ than for the $\mathrm{PV}-1-$ trace $\left(0.77 \mathrm{~s}^{-1}\right)$. These results indicate that PV severely curtails the amplitude and duration of $\left[\mathrm{Ca}^{2+}\right]_{\mathrm{i}}$ transients by binding $\mathrm{Ca}^{2+}$ after a $\mathrm{Ca}_{i}^{2+}$ rise, particularly at room temperature, where other extrusion systems $\left(\mathrm{Ca}^{2+}\right.$-ATPases $)$ are less efficient. In the absence of this protein, $\mathrm{Ca}_{\mathrm{i}}^{2+}$ removal is

\section{A}

\section{Spike-triggered averages}
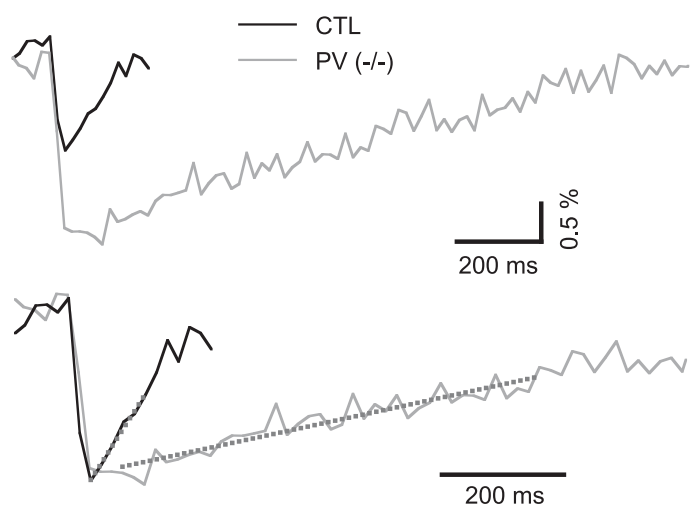

B PV (-/-)
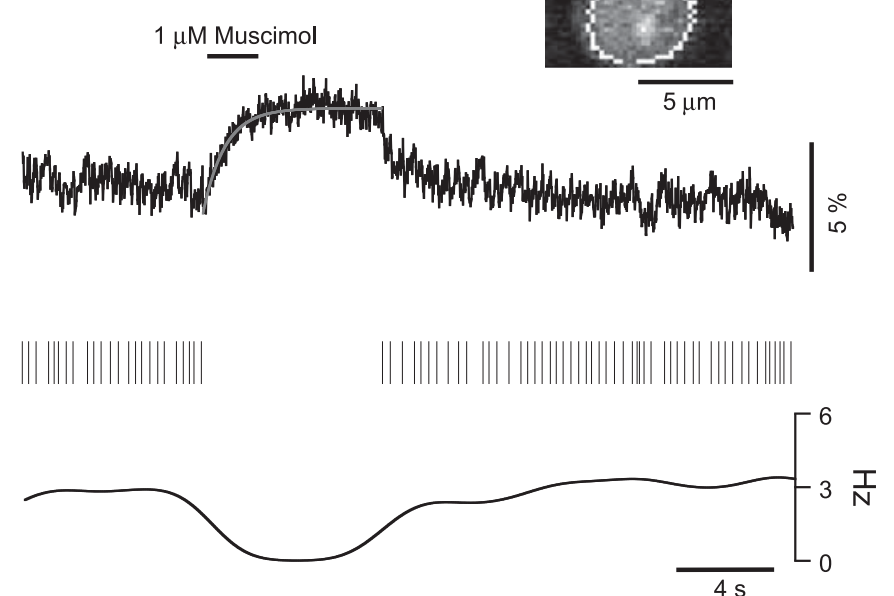

Fig. 4. Regulation by parvalbumin (PV) of spike-related intracellular $\mathrm{Ca}^{2+}$ concentration $\left(\left[\mathrm{Ca}^{2+}\right]_{\mathrm{j}}\right)$. A, top: spike-triggered averages obtained from PV $-/-$ MLIs (gray trace) and from control MLIs (black trace; same data as used for Fig. 2B). For the PV $-/-$ trace averages of 5 individual cells were first constructed from sweeps in which no firing occurred in the $500 \mathrm{~ms}$ preceding and the $2 \mathrm{~s}$ following the spike. These averages were then pooled together to yield the displayed average. Bottom: both traces are shown after normalization to a peak amplitude of 1 . The gray dashed line corresponds to the fit of the data by a linear function. $B$ : muscimol-silencing experiment in a $\mathrm{PV}-/-$ MLI. The gray solid line superimposed on the fluorescence trace presents the fit of the data points during the pause in spiking by a single exponential function. The time constant obtained by fit was $0.93 \mathrm{~s}$. Data from $A$ and $B$ are from experiments performed at room temperature. done exclusively by the extrusion systems, which are quite inefficient in the low $\mathrm{Ca}_{i}^{2+}$ range. Thus the speed at which $\left[\mathrm{Ca}^{2+}\right]_{\mathrm{i}}$ returns to basal levels for small $\left[\mathrm{Ca}^{2+}\right]_{\mathrm{i}}$ elevations is very slow in $\mathrm{PV}-/-$ cells.

In line with previous experiments, we expected that PV deletion would speed up the time constant of decay of the fluorescence relaxations accompanying muscimol-induced silencing. With this protocol we look at the speed at which the extrusion systems are able to decrease $\left[\mathrm{Ca}^{2+}\right]_{\mathrm{i}}$. While the presence of PV is not expected to modify the steady-state $\left[\mathrm{Ca}^{2+}\right]_{\mathrm{i}}$ observed before muscimol, or the rate of extrusion of $\mathrm{Ca}^{2+}$ ions by the plasma membrane pumps/exchangers, $\mathrm{Ca}^{2+}$ ions removed from the cytosol because of the clearance systems are constantly replenished by $\mathrm{Ca}^{2+}$ ions released from $\mathrm{PV}$, so that PV effectively slows down the rate of decrease of $\left[\mathrm{Ca}^{2+}\right]_{\mathrm{i}}$. The experimental results confirm this hypothesis. The relaxations observed in muscimol-induced silencing experiments had time constants of decay significantly faster in the PV $-/-$ cells, with average $\tau$ of $2.01 \pm 0.15 \mathrm{~s}$ (32 applications from 7 cells; example in Fig. 4B) compared with the control values of $3.26 \pm 0.22 \mathrm{~s}$ (68 applications from 22 cells; room temperature experiments for both groups; 1-sided Welch's $t$-test $P=5 \times 10^{-6}$ ).

\section{Assessing Indicator Effects}

Fura-2 is a high-affinity $\mathrm{Ca}^{2+}$ buffer, so $\left[\mathrm{Ca}^{2+}\right]_{\mathrm{i}}$ fluctuations are expected to be blunted at high fura- 2 concentrations. On the other hand, MLIs contain PV at a concentration in the 100-200 $\mu \mathrm{M}$ range (Collin et al. 2005). Since PV is a high-affinity $\mathrm{Ca}^{2+}$ buffer, unless very large fura- 2 concentrations were involved in the present experiments, its buffering capacity should predominate. Nevertheless, the potential impact of dye buffering and of the AM-loading procedure on the muscimol responses were examined experimentally. First, we estimated the dye concentration in AM experiments from curves relating normalized photon counts to fura- 2 concentration that were obtained from MLIs loaded by WCR with the $\mathrm{K}^{+}$form of fura- 2 . The slope for the relation extracted from those data was used to convert normalized photon counts in AM-loaded cells to fura-2 concentration. As discussed elsewhere, this type of comparison across experiments is possible because of the confocal nature of the two-photon excitation, provided that experiment-toexperiment differences in excitation and recording parameters are accounted for (Conti et al. 2004). The mean concentration of fura- 2 estimated in this manner was $56 \pm 14 \mu \mathrm{M}(n=24)$ at room temperature and $23 \pm 6 \mu \mathrm{M}(n=12)$ at $34^{\circ} \mathrm{C}$, markedly smaller than the PV concentration for MLIs. Pooled data on muscimol silencing experiments conducted at both temperatures are shown in Fig. 5, where the changes in fluorescence were normalized to the number of spikes in the second preceding the puff to yield the integral of the $\mathrm{Ca}^{2+}$ change. This parameter shows no change as a function of the estimated fura- 2 concentration (Fig. 5A). Additionally, there was no correlation between $\tau$ and the estimated fura- 2 concentration (Fig. 5B). Collectively, these results suggest that the additional $\mathrm{Ca}^{2+}$ buffering capacity associated with the AM loading protocol does not significantly affect the amplitude or time course of the fluorescence transients.

We next tested for potential complications that can arise if the AM-loaded indicator is internalized into the cell organelles 
A

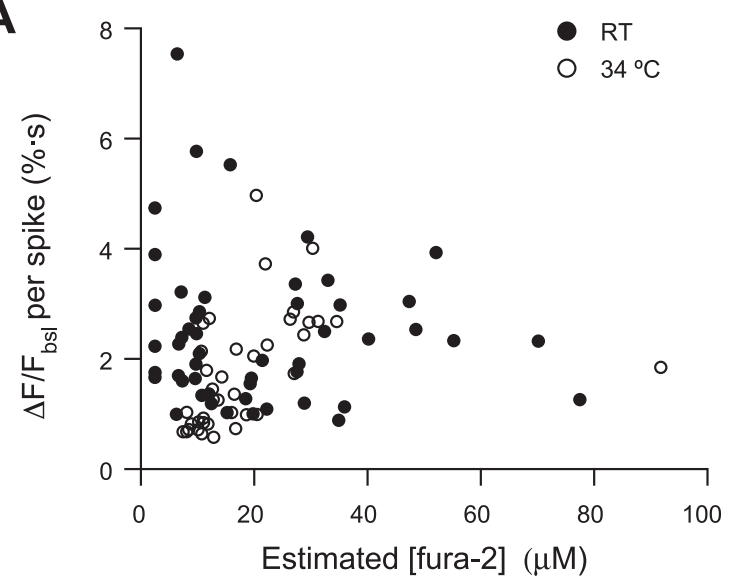

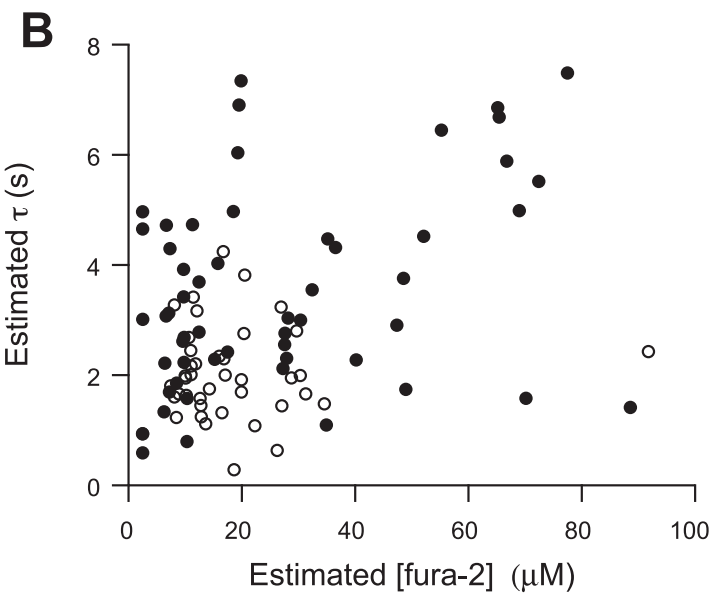

D

C Fura-2 pipette load

$1 \mu \mathrm{M}$ Muscimol

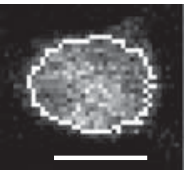

$5 \mu \mathrm{m}$

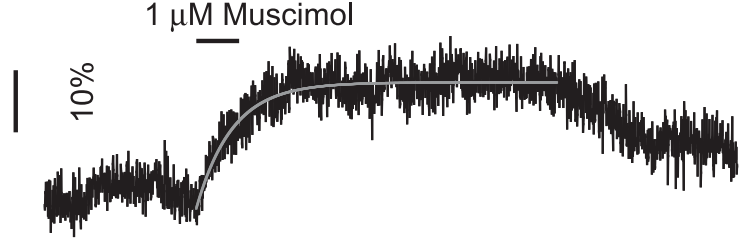

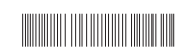

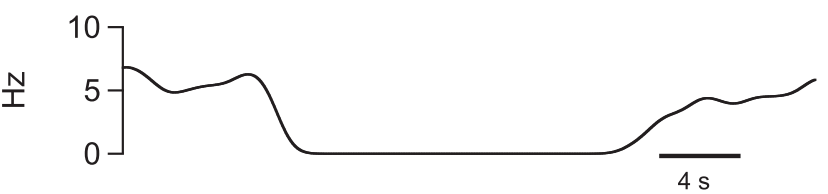

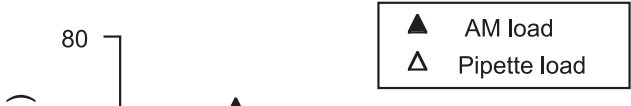

$\Delta$

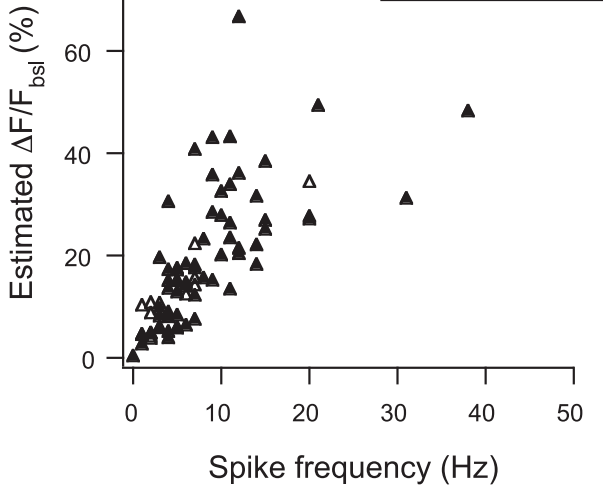

Fig. 5. Lack of effects of fura-2 concentration and of AM loading. A: muscimol-evoked changes in fluorescence normalized to the spike frequency in the second preceding the puff are plotted against fura- 2 concentration. Filled circles denote 65 runs from 24 cells studied at room temperature and open circles 39 runs from 12 cells studied at $34^{\circ} \mathrm{C}$. $B$ : plots of decay time constants $(\tau)$ as a function of estimated fura- 2 concentration for the same data set. $C$ : example of a muscimol-induced spike silencing experiment in which fura-2 was introduced with a patch pipette during a short whole cell recording (WCR). Top: temporal course of the muscimol-induced changes in fluorescence quantified in the somatic region delimited by the contour on the image and raster plot for the spikes recorded in the cell-attached configuration. Bottom: instantaneous firing frequency. $D$ : plots of the estimated muscimol-induced changes in fluorescence against spike frequency at room temperature for AM-loaded MLIs (filled triangles; same data set as that shown in Fig. $3 B$ ) and for MLIs preloaded with fura-2 by short WCR (open triangles; 11 runs from 3 cells).

(Thomas et al. 2000). To control for this possibility, muscimol spike silencing experiments were performed on MLIs that had not been submitted to AM loading but were preloaded with the fura- $2 \mathrm{~K}^{+}$salt by a short WCR and were subsequently repatched to record the spike activity in the cell-attached mode in order to preserve endogenous components that could be subject to washout. In the context of the present work, it is important to note that it has been demonstrated that PV diffuses freely in soma and neurites of Purkinje cells (Schmidt et al. 2007). Thus the somatic levels of this protein may be rapidly altered by WCR. Because we wish to assess the amplitude and time course of activity-dependent $\left[\mathrm{Ca}^{2+}\right]_{i}$ signals in unperturbed somata, the WCR time must be kept to a minimum. These experiments used loading conditions (fura- 2 concentration 100 $\mu \mathrm{M}$, loading time $30-50 \mathrm{~s}$ ) that led to a low added $\mathrm{Ca}^{2+}$ buffer (estimated steady-state fura- 2 concentration of $<20 \mu \mathrm{M}$ ). Results from muscimol spike silencing under these conditions were similar to those obtained from AM-loaded cells (example in Fig. 5C; pooled data from 3 cells in Fig. 5D). Similarly, the peak amplitude of the spike-triggered averaged transients was $1.14 \%$ ( $n=6$; data not shown), comparable to that obtained in
AM-loaded MLIs. Taken together, the results indicate that the AM-loaded indicator was properly deesterified in the present experiments and show that the curves of Fig. $3, B$ and $C$, are independent of the loading conditions and can be used to relate $\mathrm{Ca}^{2+}$-dependent fluorescence changes and firing rate.

\section{Channels Involved in Spike-Induced $\left[\mathrm{Ca}^{2+}\right]_{i}$ Rises}

Previous work on juvenile MLIs has shown that L-type $\mathrm{Ca}^{2+}$ channels contribute to somatic $\left[\mathrm{Ca}^{2+}\right]_{\mathrm{i}}$ rises (Chavas et al. 2004; Collin et al. 2009), and recently a role for these channels in the regulation of AMPA receptor subtypes expressed in MLIs has been uncovered (Liu et al. 2010). We therefore examined the effects of the L-type channel blocker nimodipine $(20-50 \mu \mathrm{M})$ in spike silencing experiments. This type of blocker acts in a use-dependent manner (Helton et al. 2005), but in the present work the comparatively high spontaneous firing rate of MLIs ensured sufficient opening of nimodipinesensitive channels to observe a blocking action. In 2 of the 10 MLIs studied, the block was associated with a large decrease of firing rate (with ratios of frequency in nimodipine to control of 0.14 and 0.33 ), but on average this drug had no significant 
effect on spike frequency (ratio after 3-9 min in the drug over that in control: $0.80 \pm 0.13 ; P=0.11$ by paired Student's $t$-test). In contrast, there was a significant decrease in the fluorescence changes associated with muscimol as in the example shown in Fig. $6 A$ (ratio for $\Delta \mathrm{F} / \mathrm{F}_{\mathrm{bsl}}: 0.44 \pm 0.08, n=10$, $P=0.004$ by paired Student's $t$-test). Overall, nimodipine induced a significant decrease in the values of $\Delta \mathrm{F} / \mathrm{F}_{\mathrm{bsl}}$ normalized to the spike frequency, as shown by the plot in Fig. $6 B$ ( $P=0.008$ by paired Student's $t$-test).

Because ryanodine-sensitive intracellular $\mathrm{Ca}^{2+}$ stores contribute to $\left[\mathrm{Ca}^{2+}\right]_{\mathrm{i}}$ rises in MLI axons (Conti et al. 2004; Llano et al. 2000), we tested for possible involvement of these stores in somatic $\left[\mathrm{Ca}^{2+}\right]_{\mathrm{i}}$ signaling. We found that three MLIs from slices incubated with $100 \mu \mathrm{M}$ ryanodine during the AM loading period had spiking rates $(2.41 \pm 0.96 \mathrm{~Hz})$ and muscimolinduced fluorescence changes with amplitude $(10.1 \pm 1.6 \%$, $1.7 \pm 0.5 \% \cdot \mathrm{s}$ when normalized to the spike rate) and decay time constant $(2.42 \pm 0.160 \mathrm{~s})$ comparable to the parameters obtained in control MLIs (room temperature experiments).

These results suggest that L-type $\mathrm{Ca}^{2+}$ channels subserve spike-related somatic $\left[\mathrm{Ca}^{2+}\right]_{i}$ rises. The lack of effect of ryanodine argues against a role for $\mathrm{Ca}^{2+}$-induced $\mathrm{Ca}^{2+}$ release in somatic spike signaling. Since P-type $\mathrm{Ca}^{2+}$ channels are responsible for the $\left[\mathrm{Ca}^{2+}\right]_{\mathrm{i}}$ rises occurring in the axonal domain during cell firing (Forti et al. 2000), $\mathrm{Ca}^{2+}$ channels in MLIs appear to be spatially segregated.

\section{Somatic $\left[\mathrm{Ca}^{2+}\right]_{i}$ Signals from MLIs in Vivo}

To probe the excitability of MLIs in vivo by somatic $\left[\mathrm{Ca}^{2+}\right]_{\mathrm{i}}$ imaging, we implemented the bolus-loading technique (Stosiek et al. 2003) to introduce AM indicators into the cerebella of anesthetized mice. Pilot in vivo trials showed that fura- 2 yields a staining more favorable to MLIs than OGB-1 AM. Thus in three animals loaded with fura- 2 the ratio $( \pm S D)$ of average photon counts in MLIs somata to the counts in background regions was $4.52 \pm 0.95$, whereas in three animals loaded with OGB-1 the parameter was $1.43 \pm 0.13$.

With fura-2, the different cell types of the molecular layerPurkinje cells, Bergmann glial cells, and MLIs_could be identified as previously reported in rats and mice (Mukamel et al. 2009; Ozden et al. 2008, 2009; Schultz et al. 2009; Sullivan et al. 2005). Purkinje cell dendrites revealed spontaneous $\left[\mathrm{Ca}^{2+}\right]_{\mathrm{i}}$ transients at rates of $0.5-2 \mathrm{~Hz}$ and amplitudes in the $10 \%$ range (data not shown), in accord with previous reports (Ozden et al. 2009; Sullivan et al. 2005). Thus the experimental conditions used here are well suited to monitoring fast $\left[\mathrm{Ca}^{2+}\right]_{\mathrm{i}}$ transients.

Numerous somata of dimensions compatible with MLIs could be recognized in the molecular layer, as in the example displayed in Fig. 7A. Extracellular stimulation with an electrode placed within $150 \mu \mathrm{m}$ from the somata induced $\left[\mathrm{Ca}^{2+}\right]_{\mathrm{i}}$ rises in 32 cells, with peak amplitudes that increased with the stimulation intensity (example in Fig. 7B). These results are in accord with a previous report that identified changes in fluorescence reported by OGB-1 in MLIs during extracellular stimulation in vivo as arising from the release of glutamate by parallel fibers, on the basis of the dependence of the signals on stimulation parameters and pharmacological agents (Sullivan et al. 2005). These parallel fiber-evoked $\left[\mathrm{Ca}^{2+}\right]_{\mathrm{i}}$ rises are likely to involve $\mathrm{Ca}^{2+}$ influx via NMDA and/or AMPA receptors

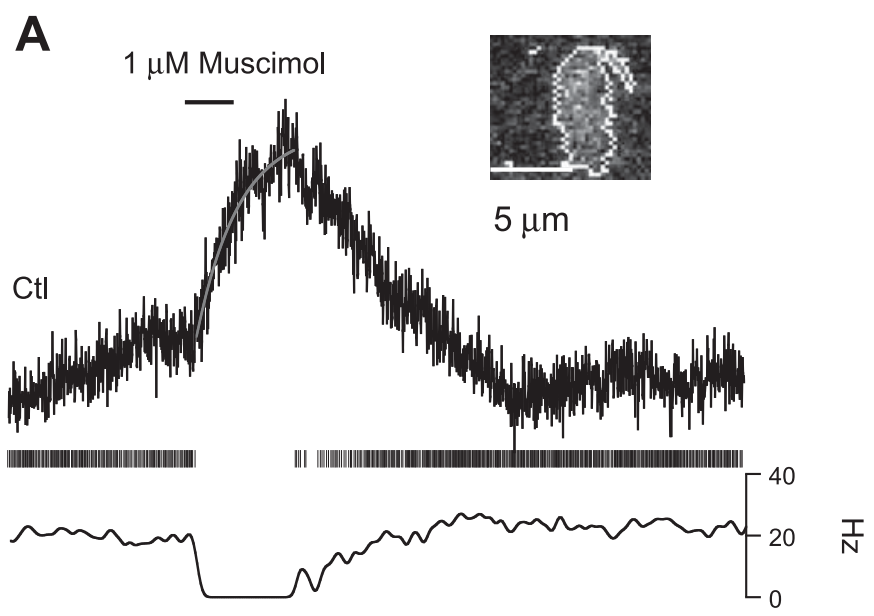

$1 \mu \mathrm{M}$ Muscimol
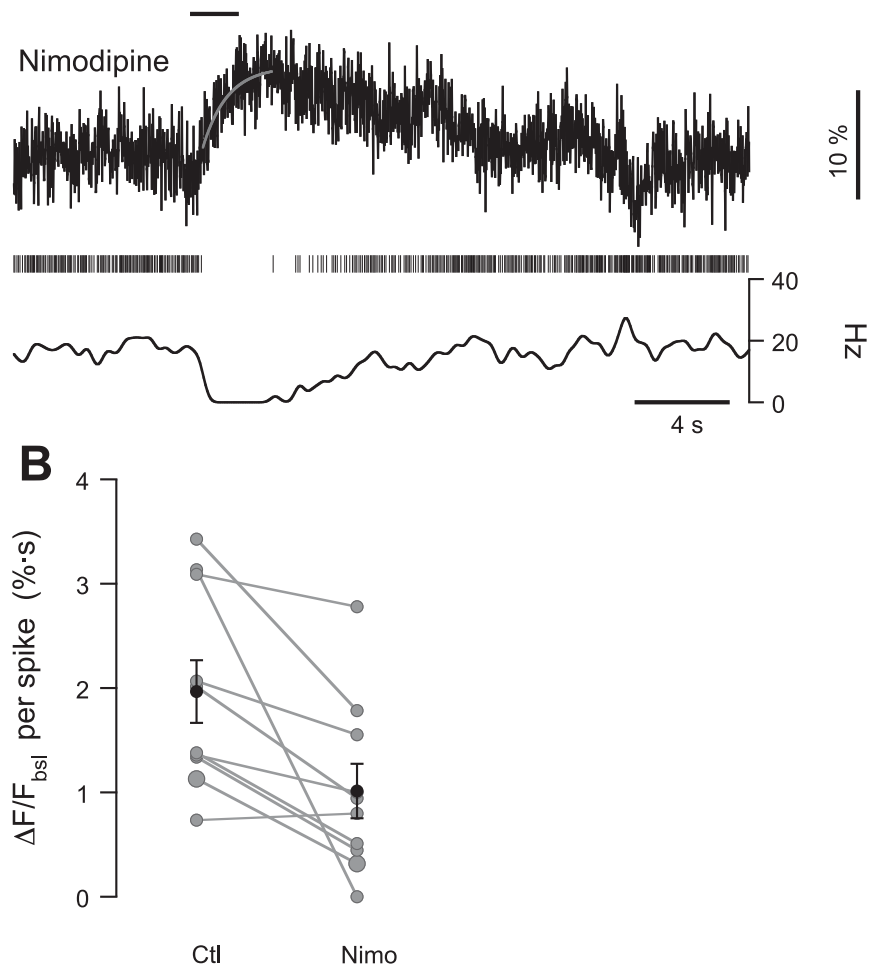

Fig. 6. L-type $\mathrm{Ca}^{2+}$ channels mediate the somatic rises. $A$ : muscimol-evoked spike silencing for a MLI in control saline (top) and $6 \mathrm{~min}$ after addition to the bath of $20 \mu \mathrm{M}$ nimodipine (bottom). In both panels, top traces plot the temporal course of the muscimol-induced changes in fluorescence quantified in the somatic region delimited by the contour on the image. The gray lines correspond to exponential fits of the data, with $\tau$ values of $1.9 \mathrm{~s}$ in the control trace and $1.1 \mathrm{~s}$ in the nimodipine trace. The bottom traces present the raster plot for the spikes recorded in the cell-attached configuration, and the plots at bottom report the instantaneous firing frequency. Spike rates are $18 \mathrm{~Hz}$ in control and $17 \mathrm{~Hz}$ in nimodipine. Note that at the timescale displayed, individual spikes cannot be resolved. $B$ : pooled data on the effects of nimodipine on spike-related $\left[\mathrm{Ca}^{2+}\right]_{\mathrm{i}}$ rises assessed by muscimol-silencing experiments. Gray dots correspond to the muscimol-evoked change in fluorescence normalized to the spike frequency in the second preceding the puff, in control saline, and 3-7 min after addition of $20-50 \mu \mathrm{M}$ nimodipine to the bath. Each pair of circles represents 1 MLI. Black circles plot the means \pm SE for the data set. 
Fig. 7. In vivo $\mathrm{Ca}^{2+}$ imaging from MLIs. A: 2PLSM image of a field of the molecular layer in the vermis of a PN31 anesthetized mouse. $B$ : changes in fluorescence induced by focal extracellular stimulation at $10 \mathrm{~Hz}$ for 1 $\mathrm{s}$, as indicated by the black bar above the traces. Fluorescence was quantified in the region delimited by the contour shown on the image on left. $C$ : reference image for the targeted path scanning trajectory on the molecular layer. Six somata were targeted for scanning at high temporal resolution (1.2 ms per soma, dwell time for the trajectory: $12.7 \mathrm{~ms}$ ). Right: average fluorescence for each soma as a function of time (in gray), as well as smoothed versions of the same data (with colors corresponding to those of the arrows in the reference image). Data were collected in the pixels on the purple lines on the reference image.
A
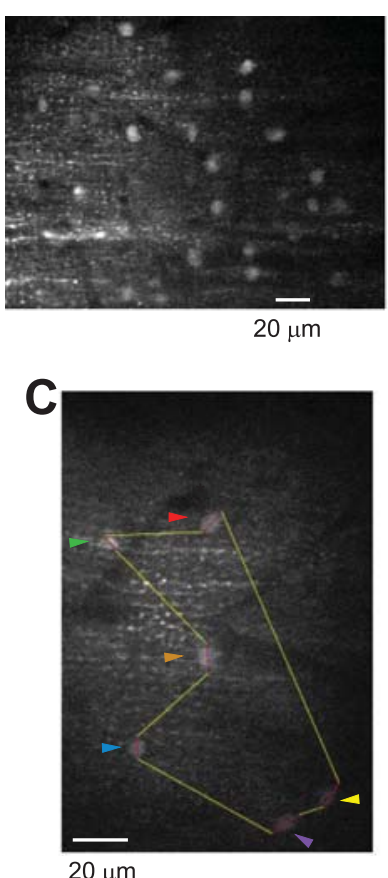

B

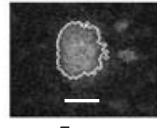

$5 \mu \mathrm{m}$
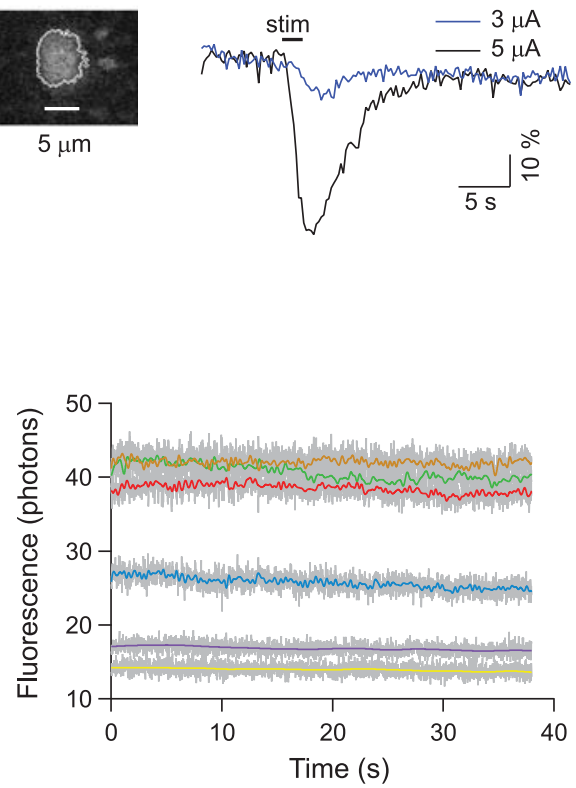

since both receptors are present at MLIs and are known to be $\mathrm{Ca}^{2+}$ permeable in these neurons (Carter and Regehr 2000; Liu and Cull-Candy 2000; Rossi et al. 2008; Shin and Linden 2005).

Despite the robust responses to extracellular stimulation, no spontaneous fluorescence fluctuations were observed in MLI somata in vivo. A representative experiment is displayed in Fig. $7 C$, where TPS (see MATERIALS AND METHODS) was used to follow the somatic fluorescence in six MLIs with $12.7-\mathrm{ms}$ temporal resolution. Among hundreds of putative interneurons recorded in this manner, only two displayed clearly identifiable fluctuations. We conclude therefore that strongly bursting MLIs are not present in the preparations studied. The question that arises then is whether the lack of fluorescence fluctuations denotes a lack of action potential firing in the anesthetized preparation or whether it reflects the behavior of tonically firing MLIs as observed in vitro (Figs. $1 C$ and $2 A$ ). The second option is favored by the fact that spontaneous firing by MLIs was observed with extracellular recordings in the decerebrated cat in vivo (Eccles et al. 1966; Jörntell and Ekerot 2003) and in anesthetized mice (Barmack and Yakhnitsa 2008).

\section{Muscimol Silencing in Vivo}

From our in vitro data we predict that if MLIs indeed fire tonically in vivo, silencing the spikes by muscimol exposure should result in slow and transient fluorescence relaxations. Initial attempts to validate the hypothesis by using muscimol puffs failed because of the difficulty in controlling movement artifacts when puffing into compact tissue. In a single experiment that was free of such artifacts, we observed an increase of fluorescence of $15 \%$.

To circumvent the movement artifacts, we resorted to silencing MLIs by iontophoresis of muscimol (see MATERIALS AND METHODS). In 7 of 11 cells (see example in Fig. 8), iontophoretic applications of muscimol at $0.5 \mathrm{mM}$ induced clear monoexponential relaxations similar to those observed in slices. We applied the analysis procedures used for MLIs in slices to the muscimol-induced relaxations. This yielded mean $\Delta \mathrm{F} / \mathrm{F}_{\mathrm{bsl}}$ estimates of $19.6 \pm 2.9 \%$ and mean decay $\tau$ of $2.9 \pm 0.3 \mathrm{~s}(10$ muscimol applications on 7 cells from 2 experiments). The range of estimated $\Delta \mathrm{F} / \mathrm{F}_{\mathrm{bsl}}$ values $(6.9-37.1 \%)$ corresponds to spiking frequencies ranging from 2 to $30 \mathrm{~Hz}$. This window is in agreement with values previously reported in vivo (Armstrong and Rawson 1979; Barmack and Yakhnitsa 2008; Eccles et al. 1966). These results indicate that the silencing method can be used to assess activity levels in vivo.

\section{DISCUSSION}

\section{Somatic Calcium Signaling in Interneurons}

In excitatory neurons of the neocortex (Kerr et al. 2005) and hippocampus (Sasaki et al. 2008) simultaneous optical and electrophysiological recordings of the spontaneous activity, similar to those performed here, reveal that individual action potentials result in a significant increase in the $\mathrm{Ca}^{2+}$-dependent

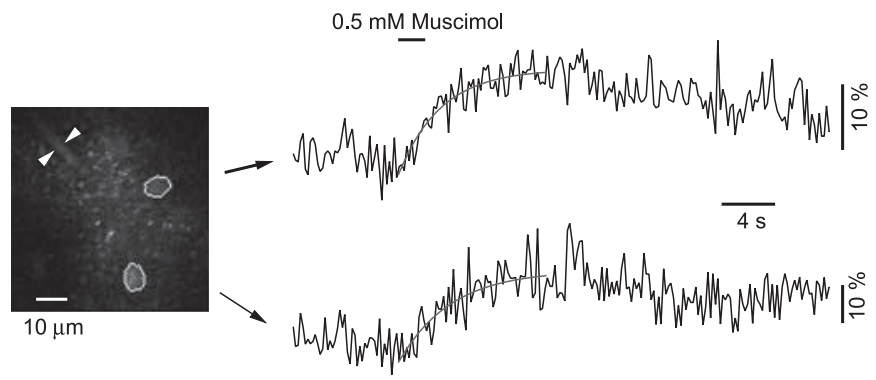

Fig. 8. Muscimol silencing in vivo. Iontophoretic application of $0.5 \mathrm{mM}$ muscimol was performed at the time indicated by the bar above the traces. The pipette position is denoted by arrowheads in the image on left. The traces correspond to the muscimol-evoked changes in fluorescence in the regions of the two MLIs delimited by the contours on the image on left. Fits of the relaxation yield $\tau$ values of $3.8 \mathrm{~s}$ and $3.1 \mathrm{~s}$ for the top and bottom traces, respectively. 
somatic fluorescence, $\sim 10 \%$ per spike with indicators with an affinity similar to that of fura-2. By contrast, the corresponding fluorescence changes in cerebellar MLIs are on the order of $1 \%$. Our results are consistent with the recent report that relative changes in somatic fluorescence per spike are $<1 \%$ in PV-positive cortical interneurons, whereas they are $\sim 10 \%$ in their excitatory counterparts (Kerlin et al. 2010). In Purkinje cells, another PV-positive cell type, somatic $\left[\mathrm{Ca}^{2+}\right]_{\mathrm{i}}$ signals associated with simple spikes are also small (Lev-Ram et al. 1992; Miyakawa et al. 1992), in accord with electrophysiological data showing that $\mathrm{Ca}^{2+}$ spikes have a dendritic localization (Llinás and Sugimori 1980a, 1980b). One may speculate that low-amplitude signals are rendered necessary by the relative high spiking frequencies observed in those cells. Larger signals would end up in the accumulation of potentially deleterious levels of somatic calcium. In Purkinje cells, the low signal amplitude may be related to the fact that spikes are very fast in these neurons, with reported widths in the 150-400 $\mu$ s range (review by Bean 2007), and the voltage change may therefore be insufficient to bring voltage-gated $\mathrm{Ca}^{2+}$ channels to threshold. This reasoning is, however, unlikely to apply to MLIs, since their spikes are in the 1-ms width range (Mann-Metzer and Yarom 2002), similar to that of pyramidal neurons in the hippocampus (review by Bean 2007). It is worth noting that MLI $\left[\mathrm{Ca}^{2+}\right]_{i}$ somatic signals are much smaller than those associated with individual spikes in axonal varicosities when these neurons are preloaded with a high-affinity $\mathrm{Ca}^{2+}$ indicator and subjected to cell-attached recording (Conti et al. 2004). Therefore, the most likely explanation for the difference between MLIs and glutamatergic neurons in cortex and hippocampus is a low density of somatic $\mathrm{Ca}^{2+}$ channels as postulated from earlier imaging work in MLIs (Llano et al. 1997).

Taken together these results suggest that different modes of spike-evoked somatic $\left[\mathrm{Ca}^{2+}\right]_{\mathrm{i}}$ signaling occur in inhibitory interneurons and in excitatory neurons of the hippocampus and cortex. In the latter cells, the spontaneous spiking rate is low and each spike is accompanied by a clear individual $\left[\mathrm{Ca}^{2+}\right]_{\mathrm{i}}$ transient. By contrast, in MLIs, individual $\left[\mathrm{Ca}^{2+}\right]_{i}$ signals cannot be distinguished and $\left[\mathrm{Ca}^{2+}\right]_{i}$ evolves gradually accordingly to the firing rate. Thus the fluorescence reflects the integral of the action potential activity rather than the activity itself.

\section{Role of PV in Shaping Spike-Induced $\left[\mathrm{Ca}^{2+}\right]_{i}$ Rises}

MLIs possess relatively high concentrations of $\mathrm{PV}$, which confer a marked biexponential decay to axonal $\left[\mathrm{Ca}^{2+}\right]_{\mathrm{i}}$ transients following action potentials (Collin et al. 2005). PV furthermore slows down $\mathrm{Ca}^{2+}$ diffusion, a process likely to contribute to the strong spatial segregation that rules action potential-evoked axonal $\left[\mathrm{Ca}^{2+}\right]_{\mathrm{i}}$ signals (Forti et al. 2000) as well as dendritic $\left[\mathrm{Ca}^{2+}\right]_{\mathrm{i}}$ rises evoked by stimulation of parallel fibers (Soler-Llavina and Sabatini 2006).

The physiological role of a cytosolic $\mathrm{Ca}^{2+}$ buffer depends on its ability to shape a $\left[\mathrm{Ca}^{2+}\right]_{\mathrm{i}}$ signal, which is dictated by its $\mathrm{Ca}^{2+}$-binding properties, i.e., the affinity for $\mathrm{Ca}^{2+}$ and other metal ions, the kinetic binding parameters (on/off rates), the concentration within the compartment of interest, and the mobility of the $\mathrm{Ca}^{2+}$ buffer. These properties are well studied for PV (for reviews, see Schwaller 2009, 2010). It must be considered that, besides binding $\mathrm{Ca}^{2+}$ following a $\left[\mathrm{Ca}^{2+}\right]_{i}$ transient, every $\mathrm{Ca}^{2+}$ buffer also serves as a $\mathrm{Ca}^{2+}$ source at a later time point. The role of $\mathrm{PV}$ as a $\mathrm{Ca}^{2+}$ source was studied in a murine PV-expressing fast-twitch muscle subjected to tetanic stimulation. It was found that in wild-type muscles the relaxation rate depends on tetanus duration, whereas this does not occur in muscles from $\mathrm{PV}-/-$ mice (Raymackers et al. 2000). Thus the fraction of $\mathrm{Ca}^{2+}$-bound PV resulting from an increase in tetanic stimulation determines the relaxation rate. In analogy, in the muscimol experiments the relaxation of fluorescence to resting levels after spike silencing by muscimol is faster in the PV-/- animals because PV is no longer present to act as a $\mathrm{Ca}^{2+}$ source.

Although the kinetic changes we observed were expected from the properties of PV, the fact that PV changed not only the time course but also the maximal amplitude of the $\left[\mathrm{Ca}^{2+}\right]_{\mathrm{i}}$ rises derived from single spikes (spike-triggered averages) came as a surprise because PV is generally considered to be too slow to affect the rising phase of a $\left[\mathrm{Ca}^{2+}\right]_{i}$ transient. In the MLIs analyzed here PV behaved, in part, like a fast $\mathrm{Ca}^{2+}$ buffer such as calbindin-D28k or BAPTA. At a given $\left[\mathrm{Ca}^{2+}\right]_{i}$ and $\left[\mathrm{Mg}^{2+}\right]_{\mathrm{i}} \mathrm{PV}$ molecules inside a cell exist in different forms: $\mathrm{Mg}^{2+}$-bound $\mathrm{PV}, \mathrm{Ca}^{2+}$-bound $\mathrm{PV}$, and metal-free (apo)-PV. The latter is characterized by high affinity $\left(K_{\mathrm{d}} \approx 5-9\right.$ $\mathrm{nM}$; Eberhard and Erne 1994) and a fast $\mathrm{Ca}^{2+}$ binding rate $\left(k_{\text {on, } \mathrm{Ca}} \approx 1 \times 10^{8} \mathrm{M}^{-1} \mathrm{~s}^{-1}\right.$; Lee et al. 2000; Schmidt et al. 2003). At resting $\left[\mathrm{Ca}^{2+}\right]_{\mathrm{i}}$ in the range of $50 \mathrm{nM}$ and with $\mathrm{PV}$ concentration estimated to be between $50 \mu \mathrm{M}$ in Purkinje cells (Schmidt et al. 2003) and $150 \mu \mathrm{M}$ in MLIs (Collin et al. 2005) the fraction of the "fast," metal-free form of PV was considered too low to affect the early phase of $\left[\mathrm{Ca}^{2+}\right]_{i}$ transients. More recent measurements in murine MLIs indicate that PV concentrations reach values on the order of $0.5 \mathrm{mM}$ (E. Eggermann and P. Jonas, personal communication). At those concentrations, the fraction of apo-PV can correspond to a nonnegligible amount of PV molecules $(\sim 25-50 \mu \mathrm{M}$ at $\left[\mathrm{Ca}^{2+}\right]_{\mathrm{i}}$ of $50 \mathrm{nM}$; Schmidt et al. 2003) that, by acting as a fast $\mathrm{Ca}^{2+}$ buffer, can reduce the maximal amplitude of $\left[\mathrm{Ca}^{2+}\right]_{\mathrm{i}}$ elevations in MLIs. That PV may also act as a fast buffer under certain conditions (small $\left[\mathrm{Ca}^{2+}\right]_{\mathrm{i}}$ signals, high intracellular $[\mathrm{PV}]$ ) is a novel and unexpected finding from our experiments in MLIs. This is in contrast to the action of the synthetic buffer EGTA, often used in experiments to mimic the role of PV. Even high EGTA concentrations will not lead to a "PV-like" behavior with respect to fast binding kinetics.

\section{Using Muscimol for Spike Silencing}

Injections of muscimol in the cortex of rats in vivo have been previously used to stop neuronal firing for extended periods of time (several hours) in order to dissect the contribution of specific pathways to information processing (Liu et al. 2007). In the rat cerebellum in vivo, activation of $\mathrm{GABA}_{\mathrm{A}}$ receptors lasting 1-2 $\mathrm{h}$ was achieved by topical superfusion of muscimol at the pial surface, which reduces by $>90 \%$ the firing rate of Purkinje cells and allowed the study of the relation between metabolic and electrophysiological parameters (Caesar et al. 2003). Here we use the activation of $\mathrm{GABA}_{\mathrm{A}}$ receptors in a much shorter time window and show that muscimol is very efficient to induce transient silencing of MLIs. Because muscimol-induced spike silencing with the low dose and short exposure time of the present work is fast and 
reversible, it allows the monitoring of neuronal activity for extended periods of time.

Applying the muscimol-induced spike silencing strategy to the in vivo situation allowed us to estimate the firing frequency range for MLIs in anesthetized mice. This approach, however, has limitations. The levels of inhibition are likely to depend on pipette position. Thus, when no response is observed, it is not clear whether the cell is not spiking or whether the local muscimol concentration is too weak to stop firing. It was not possible to address this issue experimentally by simply raising the muscimol concentration because muscimol could then become excitatory as previously described in slices (Chavas et al. 2004).

An important conclusion from the present work is that, in certain types of neurons, a good method for rapid silencing is required to relate the firing activity with $\left[\mathrm{Ca}^{2+}\right]_{\mathrm{i}}$ imaging data. As an alternative to muscimol iontophoresis, light-gated delivery of GABA agonists would be desirable to extend the applicability of the present spike silencing approach for in vivo studies of neuronal excitability. A $\mathrm{GABA}_{\mathrm{A}}$ cage suitable for 2PLSM has been recently described (Matsuzaki et al. 2010), but its pharmacological properties remain to be rigorously tested. This is important since $\mathrm{GABA}_{\mathrm{A}}$ cages can have significant pharmacological effects (Trigo et al. 2009). Another attractive option is the use of opsin transgenes to silence cells (Zhang et al. 2007). Optogenetic tools would ideally allow turning off transiently the entire MLI network studied without potential pharmacological complications and without affecting other cell populations.

In vivo, additional complications for the interpretation of signals from $\left[\mathrm{Ca}^{2+}\right]_{\mathrm{i}}$ reporters in terms of electrical activity can arise from the constant synaptic bombardment of neurons. $\left[\mathrm{Ca}^{2+}\right]_{\mathrm{i}}$ is likely to rise in the soma through AMPA and NMDA receptors opened after glutamate is released at parallel fiber synapses (Carter and Regehr 2000; Cull-Candy et al. 2006). Understanding how synaptic and spike-related $\left[\mathrm{Ca}^{2+}\right]_{\mathrm{i}}$ signals interact in the somatic compartment will be a central question for studies of MLI signaling.

\section{Possible Functional Role of Somatic $\left[\mathrm{Ca}^{2+}\right]_{i}$ Signals}

Encoding electrical activity into $\left[\mathrm{Ca}^{2+}\right]_{\mathrm{i}}$ changes is generally thought to have a homeostatic purpose such that somatic $\left[\mathrm{Ca}^{2+}\right]_{\mathrm{i}}$ changes instruct individual genes to make necessary adjustments as a function of the level of activity. As an early example of this homeostatic principle, blocking $\mathrm{Ca}^{2+}$ influx in neuroblastoma cells was shown to result in a compensatory increase in the expression of somatodendritic voltage-dependent $\mathrm{Ca}^{2+}$ channels (Passafaro et al. 1994). In cerebellar stellate cells, the subunit composition of AMPA receptors, which determines their permeability to $\mathrm{Ca}^{2+}$ (Geiger et al. 1995), changes as a result of synaptic activity, providing another example of homeostatic regulation (Liu and CullCandy 2000). Recently, it has been proposed that gene transcription dependent on $\mathrm{Ca}^{2+}$ influx via L-type $\mathrm{Ca}^{2+}$ channels is required for the switch in AMPA receptor phenotype (Liu et al. 2010). The integrative character of the somatic $\left[\mathrm{Ca}^{2+}\right]_{\mathrm{i}}$ in MLIs makes this signal directly appropriate for such a homeostatic role.

\section{ACKNOWLEDGMENTS}

We thank Alain Marty and Thibault Collin for valuable discussions and for comments on the manuscript and Christophe Pouzat, Sébastien Joucla, and Tiffany Lieury for helpful discussions on analysis procedures.
Present address of R. Franconville: Janelia Farm Research Campus, Howard Hughes Medical Institute, 19700 Helix Drive, Ashburn, VA 20147.

\section{GRANTS}

This work was supported by the Centre National de la Recherche Scientifique (CNRS), by a grant from the Agence National de la Recherche (BLAN08-2_313083), and by a fellowship from the "Fondation pour la Recherche Médicale" to R. Franconville.

\section{DISCLOSURES}

No conflicts of interest, financial or otherwise, are declared by the author(s).

\section{REFERENCES}

Armstrong DM, Rawson JA. Activity patterns of cerebellar cortical neurones and climbing fibre afferents in the awake cat. J Physiol 289: 425-448, 1979. Barmack NH, Yakhnitsa V. Functions of interneurons in mouse cerebellum. J Neurosci 28: 1140-1152, 2008.

Bean BP. The action potential in mammalian central neurons. Nat Rev Neurosci 8: 451-465, 2007.

Brini M, Carafoli E. The plasma membrane $\mathrm{Ca}^{2+}$ ATPase and the plasma membrane sodium calcium exchanger cooperate in the regulation of cell calcium. Cold Spring Harb Perspect Biol 3: a004168, 2011.

Caesar K, Thomsen K, Lauritzen M. Dissociation of spikes, synaptic activity, and activity-dependent increments in rat cerebellar blood flow by tonic synaptic inhibition. Proc Natl Acad Sci USA 100: 16000-16005, 2003.

Carter AG, Regehr WG. Prolonged synaptic currents and glutamate spillover at the parallel fiber to stellate cell synapse. J Neurosci 20: 4423-4434, 2000.

Chavas J, Forero ME, Collin T, Llano I, Marty A. Osmotic tension as a possible link between $\mathrm{GABA}_{\mathrm{A}}$ receptor activation and intracellular calcium elevation. Neuron 44: 701-713, 2004.

Chen T, Lin B, Brunner E, Schild D. In situ background estimation in quantitative fluorescence imaging. Biophys J 90: 2534-2547, 2006.

Collin T, Chat M, Lucas MG, Moreno H, Racay P, Schwaller B, Marty A, Llano I. Developmental changes in parvalbumin regulate presynaptic $\mathrm{Ca}^{2+}$ signaling. J Neurosci 25: 96-107, 2005.

Collin T, Franconville R, Ehrlich BE, Llano I. Activation of metabotropic glutamate receptors induces periodic burst firing and concomitant cytosolic $\mathrm{Ca}^{2+}$ oscillations in cerebellar interneurons. J Neurosci 29: 9281-9291, 2009.

Conti R, Tan YP, Llano I. Action potential-evoked and ryanodine-sensitive spontaneous $\mathrm{Ca}^{2+}$ transients at the presynaptic terminal of a developing CNS inhibitory synapse. J Neurosci 24: 6946-6957, 2004.

Cull-Candy S, Kelly L, Farrant M. Regulation of $\mathrm{Ca}^{2+}$-permeable AMPA receptors: synaptic plasticity and beyond. Curr Opin Neurobiol 16: $288-$ 297, 2006.

Eberhard M, Erne P. Calcium and magnesium binding to rat parvalbumin. Eur J Biochem 222: 21-26, 1994.

Eccles JC, Llinás R, Sasaki K. The inhibitory interneurones within the cerebellar cortex. Exp Brain Res 1: 1-16, 1966.

Engel D, Jonas P. Presynaptic action potential amplification by voltage-gated $\mathrm{Na}^{+}$channels in hippocampal mossy fiber boutons. Neuron 45: 405-417, 2005.

Fierro L, DiPolo R, Llano I. Intracellular calcium clearance in Purkinje cell somata from rat cerebellar slices. J Physiol 510: 499-512, 1998.

Forti L, Pouzat C, Llano I. Action potential-evoked $\mathrm{Ca}^{2+}$ signals and calcium channels in axons of developing rat cerebellar interneurones. J Physiol 527: 33-48, 2000.

Garaschuk O, Milos R, Grienberger C, Marandi N, Adelsberger H, Konnerth A. Optical monitoring of brain function in vivo: from neurons to networks. Pflügers Arch 453: 385-396, 2006 a.

Garaschuk O, Milos R, Konnerth A. Targeted bulk-loading of fluorescent indicators for two-photon brain imaging in vivo. Nat Protoc 1: 380-386, 2006b.

Geiger JR, Melcher T, Koh DS, Sakmann B, Seeburg PH, Jonas P, Monyer H. Relative abundance of subunit mRNAs determines gating and $\mathrm{Ca}^{2+}$ permeability of AMPA receptors in principal neurons and interneurons in rat CNS. Neuron 15: 193-204, 1995.

Grewe BF, Helmchen F. Optical probing of neuronal ensemble activity. Curr Opin Neurobiol 19: 520-529, 2009.

Häusser M, Clark BA. Tonic synaptic inhibition modulates neuronal output pattern and spatiotemporal synaptic integration. Neuron 19: 665-678, 1997. 
Helmchen F, Imoto K, Sakmann B. $\mathrm{Ca}^{2+}$ buffering and action potentialevoked $\mathrm{Ca}^{2+}$ signaling in dendrites of pyramidal neurons. Biophys $J$ 70: 1069-1081, 1996.

Helton TD, Xu W, Lipscombe D. Neuronal L-type calcium channels open quickly and are inhibited slowly. J Neurosci 25: 10247-10251, 2005.

Ikegaya Y, Le Bon-Jego M, Yuste R. Large-scale imaging of cortical network activity with calcium indicators. Neurosci Res 52: 132-138, 2005.

Jörntell H, Ekerot C. Receptive field plasticity profoundly alters the cutaneous parallel fiber synaptic input to cerebellar interneurons in vivo. $J$ Neurosci 23: 9620-9631, 2003.

Kerlin AM, Andermann ML, Berezovskii VK, Reid RC. Broadly tuned response properties of diverse inhibitory neuron subtypes in mouse visual cortex. Neuron 67: 858-871, 2010.

Kerr JND, Greenberg D, Helmchen F. Imaging input and output of neocortical networks in vivo. Proc Natl Acad Sci USA 102: 14063-14068, 2005.

Lee SH, Schwaller B, Neher E. Kinetics of $\mathrm{Ca}^{2+}$ binding to parvalbumin in bovine chromaffin cells: implications for $\left[\mathrm{Ca}^{2+}\right]$ transients of neuronal dendrites. J Physiol 525: 419-432, 2000

Lee SH, Ho W, Lee S. Characterization of somatic $\mathrm{Ca}^{2+}$ clearance mechanisms in young and mature hippocampal granule cells. Cell Calcium 45 465-473, 2009.

Lev-Ram V, Miyakawa H, Lasser-Ross N, Ross WN. Calcium transients in cerebellar Purkinje neurons evoked by intracellular stimulation. J Neurophysiol 68: 1167-1177, 1992.

Lillis KP, Eng A, White JA, Mertz J. Two-photon imaging of spatially extended neuronal network dynamics with high temporal resolution. $J$ Neurosci Methods 172: 178-184, 2008.

Liu B, Wu GK, Arbuckle R, Tao HW, Zhang LI. Defining cortical frequency tuning with recurrent excitatory circuitry. Nat Neurosci 10: 1594-1600, 2007.

Liu SQ, Cull-Candy SG. Synaptic activity at calcium-permeable AMPA receptors induces a switch in receptor subtype. Nature 405: 454-458, 2000

Liu Y, Formisano L, Savtchouk I, Takayasu Y, Szabó G, Zukin RS, Liu SJ. A single fear-inducing stimulus induces a transcription-dependent switch in synaptic AMPAR phenotype. Nat Neurosci 13: 223-231, 2010.

Llano I, Gerschenfeld HM. Inhibitory synaptic currents in stellate cells of rat cerebellar slices. J Physiol 468: 177-200, 1993.

Llano I, González J, Caputo C, Lai FA, Blayney LM, Tan YP, Marty A. Presynaptic calcium stores underlie large-amplitude miniature IPSCs and spontaneous calcium transients. Nat Neurosci 3: 1256-1265, 2000.

Llano I, Tan YP, Caputo C. Spatial heterogeneity of intracellular $\mathrm{Ca}^{2+}$ signals in axons of basket cells from rat cerebellar slices. J Physiol 502: 509-519, 1997.

Llinás R, Sugimori M. Electrophysiological properties of in vitro Purkinje cell somata in mammalian cerebellar slices. J Physiol 305: 171-195, 1980a.

Llinás R, Sugimori M. Electrophysiological properties of in vitro Purkinje cell dendrites in mammalian cerebellar slices. J Physiol 305: 197-213, 1980b.

Mann-Metzer P, Yarom Y. Jittery trains induced by synaptic-like currents in cerebellar inhibitory interneurons. J Neurophysiol 87: 149-156, 2002.

Manzini I, Schweer T, Schild D. Improved fluorescent (calcium indicator) dye uptake in brain slices by blocking multidrug resistance transporters. $J$ Neurosci Methods 167: 140-147, 2008.

Mao BQ, Hamzei-Sichani F, Aronov D, Froemke RC, Yuste R. Dynamics of spontaneous activity in neocortical slices. Neuron 32: 883-898, 2001.

Matsuzaki M, Hayama T, Kasai H, Ellis-Davies GCR. Two-photon uncaging of gamma-aminobutyric acid in intact brain tissue. Nat Chem Biol 6: $255-257,2010$

Midtgaard J. Membrane properties and synaptic responses of Golgi cells and stellate cells in the turtle cerebellum in vitro. J Physiol 457: 329-354, 1992.

Miyakawa H, Lev-Ram V, Lasser-Ross N, Ross WN. Calcium transients evoked by climbing fiber and parallel fiber synaptic inputs in guinea pig cerebellar Purkinje neurons. J Neurophysiol 68: 1178-1189, 1992.

Moreno H, Burghardt NS, Vela-Duarte D, Mascotti J, Hua F, Fenton AA, Schwaller B, Small SA. The absence of the calcium-buffering protein calbindin is associated with faster age-related decline in hippocampal metabolism. Hippocampus (May 31, 2011). doi: 10.1002/hipo.20957.

Mukamel EA, Nimmerjahn A, Schnitzer MJ. Automated analysis of cellular signals from large-scale calcium imaging data. Neuron 63: 747-760, 2009.

Namiki S, Sasaki T, Matsuki N, Ikegaya Y. Regional difference in stainability with calcium-sensitive acetoxymethyl-ester probes in mouse brain slices. Int J Neurosci 119: 214-226, 2009.
Oheim M, Beaurepaire E, Chaigneau E, Mertz J, Charpak S. Two-photon microscopy in brain tissue: parameters influencing the imaging depth. $J$ Neurosci Methods 111: 29-37, 2001.

Ozden I, Lee HM, Sullivan MR, Wang SS. Identification and clustering of event patterns from in vivo multiphoton optical recordings of neuronal ensembles. J Neurophysiol 100: 495-503, 2008.

Ozden I, Sullivan MR, Lee HM, Wang SS. Reliable coding emerges from coactivation of climbing fibers in microbands of cerebellar Purkinje neurons. J Neurosci 29: 10463-10473, 2009.

Passafaro M, Clementi F, Pollo A, Carbone E, Sher E. omega-Conotoxin and $\mathrm{Cd}^{2+}$ stimulate the recruitment to the plasmamembrane of an intracellular pool of voltage-operated $\mathrm{Ca}^{2+}$ channels. Neuron 12: 317-326, 1994.

Rall JA. Role of parvalbumin in skeletal muscle relaxation. News Physiol Sci 11: 249-255, 1996

Raymackers JM, Gailly P, Schoor MC, Pette D, Schwaller B, Hunziker W, Celio MR, Gillis JM. Tetanus relaxation of fast skeletal muscles of the mouse made parvalbumin deficient by gene inactivation. $J$ Physiol 527: 355-364, 2000.

Rossi B, Maton G, Collin T. Calcium-permeable presynaptic AMPA receptors in cerebellar molecular layer interneurones. J Physiol 586: 5129-5145, 2008.

Rothschild G, Nelken I, Mizrahi A. Functional organization and population dynamics in the mouse primary auditory cortex. Nat Neurosci 13: 353-360, 2010.

Sasaki T, Takahashi N, Matsuki N, Ikegaya Y. Fast and accurate detection of action potentials from somatic calcium fluctuations. J Neurophysiol 100: 1668-1676, 2008.

Sato TR, Gray NW, Mainen ZF, Svoboda K. The functional microarchitecture of the mouse barrel cortex. PLoS Biol 5: e189, 2007.

Schmidt H, Arendt O, Brown EB, Schwaller B, Eilers J. Parvalbumin is freely mobile in axons, somata and nuclei of cerebellar Purkinje neurones. J Neurochem 100: 727-735, 2007.

Schmidt H, Stiefel KM, Racay P, Schwaller B, Eilers J. Mutational analysis of dendritic $\mathrm{Ca}^{2+}$ kinetics in rodent Purkinje cells: role of parvalbumin and calbindin D28k. J Physiol 551: 13-32, 2003.

Schultz SR, Kitamura K, Post-Uiterweer A, Krupic J, Hausser M. Spatial pattern coding of sensory information by climbing fiber-evoked calcium signals in networks of neighboring cerebellar Purkinje cells. J Neurosci 29: $8005-8015,2009$

Schwaller B. The continuing disappearance of "pure" $\mathrm{Ca}^{2+}$ buffers. Cell Mol Life Sci 66: 275-300, 2009.

Schwaller B. Cytosolic $\mathrm{Ca}^{2+}$ buffers. Cold Spring Harb Perspect Biol 2 a004051, 2010.

Shin JH, Linden DJ. An NMDA receptor/nitric oxide cascade is involved in cerebellar LTD but is not localized to the parallel fiber terminal. $J$ Neurophysiol 94: 4281-4289, 2005

Soler-Llavina GJ, Sabatini BL. Synapse-specific plasticity and compartmentalized signaling in cerebellar stellate cells. Nat Neurosci 9: 798-806, 2006

Stosiek C, Garaschuk O, Holthoff K, Konnerth A. In vivo two-photon calcium imaging of neuronal networks. Proc Natl Acad Sci USA 100: $7319-7324,2003$

Sullivan MR, Nimmerjahn A, Sarkisov DV, Helmchen F, Wang SS. In vivo calcium imaging of circuit activity in cerebellar cortex. J Neurophysiol 94: $1636-1644,2005$

Tan YP, Llano I, Hopt A, Würriehausen F, Neher E. Fast scanning and efficient photodetection in a simple two-photon microscope. $J$ Neurosci Methods 92: 123-135, 1999.

Thomas D, Tovey SC, Collins TJ, Bootman MD, Berridge MJ, Lipp P. A comparison of fluorescent $\mathrm{Ca}^{2+}$ indicator properties and their use in measuring elementary and global $\mathrm{Ca}^{2+}$ signals. Cell Calcium 28: 213-223, 2000.

Trigo FF, Papageorgiou G, Corrie JET, Ogden D. Laser photolysis of DPNI-GABA, a tool for investigating the properties and distribution of GABA receptors and for silencing neurons in situ. J Neurosci Methods 181: 159-169, 2009.

Wokosin DL, Loughrey CM, Smith GL. Characterization of a range of fura dyes with two-photon excitation. Biophys J 86: 1726-1738, 2004.

Womack M, Khodakhah K. Active contribution of dendrites to the tonic and trimodal patterns of activity in cerebellar Purkinje neurons. J Neurosci 22: 10603-10612, 2002

Zhang F, Wang L, Brauner M, Liewald JF, Kay K, Watzke N, Wood PG, Bamberg E, Nagel G, Gottschalk A, Deisseroth K. Multimodal fast optical interrogation of neural circuitry. Nature 446: 633-639, 2007. 